\title{
The Saccharomyces cerevisiae Msh2 protein specifically binds to duplex oligonucleotides containing mismatched DNA base pairs and insertions
}

\author{
Eric Alani, ${ }^{1}$ Nai-Wen Chi, ${ }^{2}$ and Richard Kolodner ${ }^{3}$ \\ Division of Cellular and Molecular Biology, The Dana Farber Cancer Institute; Department of Biological Chemistry \\ and Molecular Pharmacology, Harvard Medical School, Boston, Massachusetts 02115 USA
}

The yeast Saccharomyces cerevisiae encodes four proteins, Msh1, Msh2, Msh3, Msh4, that show strong amino acid sequence similarity to MutS, a central component of the bacterial mutHLS mismatch repair system. MutS has been shown to recognize base pair mismatches in DNA in vitro. Previous studies have suggested that Msh2 is the major mismatch recognition protein in yeast. In this study, the 109-kD Msh2 polypeptide was overexpressed and purified to analyze its DNA-binding properties. This analysis demonstrated that Msh2 can bind selectively to duplex oligonucleotide substrates containing a G/T mismatch, 1- to 14-nucleotide insertion mismatches, and palindromic (12- to 14-nucleotide) insertion mismatches. A general trend was that the affinity of Msh2 for substrate was proportional to the size of the insertion mispair present (+14 PAL, +12 PAL $>+14>+8>\mathrm{GT},+6,+4,+2,+1)$. Kinetic studies indicated that the specificity of Msh2 to mismatch substrates was a function of its ability to form stable complexes with mispair-containing duplex DNAs. These complexes decayed more slowly than Msh2 complexes formed with homoduplex DNA.

[Key Words: MSH2; mismatch binding; mismatch repair; Saccharomyces cerevisiae]

Received September 14, 1994; revised version accepted December 13, 1994

Genetic recombination, DNA damage, and DNA replication errors are events that can result in the formation of base pair mismatches and insertion/deletion loops (for review, see Modrich 1991; Petes et al. 1991). If uncorrected before DNA replication, these mismatches result in mutations that become fixed in the genome. Repair systems have been identified in organisms ranging from Escherichia coli to humans. They can repair almost all base pair mismatches as well as small insertion/deletion mismatches with high efficiency (for review, see Modrich 1991; for examples, see Holmes et al. 1990; Varlet et al. 1990; Thomas et al. 1991; Reenan and Kolodner 1992a; Fishel et al. 1993; Leach et al. 1993). In E. coli it is estimated that the mutHLS mismatch repair system reduces the rate of spontaneous mutation by $\sim 1000$-fold (for review, see Modrich 1991). This basic repair system is conserved in humans and is important in preventing spontaneous mutations. Recently, it was found that defects in at least four mismatch repair genes can be correlated to an increased risk in developing nonpolyposis

Present addresses: 'Section of Genetics and Development, Cornell University, Ithaca, New York 14853 USA; ${ }^{2}$ Medical Services, Massachusetts General Hospital, Boston, Massachusetts 02114 USA.

${ }^{3}$ Corresponding author. colorectal cancer (Fishel et al. 1993; Leach et al. 1993; Parsons et al. 1993; Bronner et al. 1994; Kolodner et al. 1994; Nicolaides et al. 1994; Papadopoulos et al. 1994; Umar et al. 1994b).

The E. coli mutHLS system is the best studied of all the major mismatch repair systems and has been reconstituted from purified components (Lahue et al. 1989; for review, see Modrich 1991). Extracts have also been prepared from yeast, Xenopus, Drosphila, and human cells that can catalyze mismatch repair in vitro (Muster-Nas sal and Kolodner 1986; Holmes et al. 1990; Varlet et al. 1990; Thomas et al. 1991; Parsons et al. 1993; Umar et al. 1994b). The core recognition components of the $E$. coli system are MutS, a $97-\mathrm{kD}$ polypeptide that recognizes base pair mismatches in vitro, and MutL, a 70-kD polypeptide that is thought to dimerize and interact with MutS to increase the stability of the MutS mismatch complex. The formation of a MutS/MutL mismatch complex is thought to be required to activate $\mathrm{MutH}$, a single-strand endonuclease that recognizes and nicks the unmethylated strand of DNA at hemi-methylated GATC sites. These hemi-methylated sites are formed during replication of methylated DNA because DNA methylation is a postreplication modification. Consequently, the unmethylated strand marks transiently the 
newly replicated strand. Nicking of the unmethylated strand by MutH is then followed by the excision and resynthesis steps of mismatch repair. The net result of these interactions is a coupling of mismatch repair to DNA replication; therefore, base pair mismatches that are formed during DNA replication are repaired using the methylated parental strands as template, resulting in a reduction of misincorporation-induced errors.

The $E$. coli MutS protein has been shown to recognize base pair mismatches in vitro within the context of 20 to 120-bp duplex oligonucleotides (Su and Modrich 1986; Jiricny et al. 1988). Footprinting analysis indicated that MutS protects an $\sim 20$-bp region surrounding the base pair mismatch. Using footprint analysis, the binding affinity of MutS to a G/T mismatch, which is the most efficiently repaired mismatch in vivo, was determined to be $\sim 20 \mathrm{~nm}$. Gel shift and filter-binding assays were also used to demonstrate the specificity of MutS to substrates containing various base pair mismatches and insertions. The general finding was that base pair mismatches displayed variable binding affinities in vitro. In particular, the apparent affinity of binding was dependent on the sequence context of the base pair mismatch and did not always correlate with repair efficiencies observed in vivo. The highest specificity observed in vitro was a 10 to 40 -fold preference for a $\mathrm{G} / \mathrm{T}$ mismatch substrate over homoduplex (Jiricny et al. 1988). Loop insertion substrates were also recognized by MutS in vitro. Parker and Marinus (1992) showed that 1- to 3-nucleotide insertions were moderately recognized by Salmonella MutS, whereas 4- and 5-nucleotide insertions were poorly recognized. Interestingly, these findings correlated directly to the repair of these substrates in $E$. coli; 1 - to 3-nucleotide loop insertions were well repaired, whereas 4- to 5-nucleotide loop insertions were poorly repaired (Parker and Marinus 1992).

Homologs of mutS and mut $L$ have been identified in yeast and in mammals (Kramer et al. 1989b; Reenan and Kolodner 1992a; Fishel et al. 1993; Leach et al. 1993; New et al. 1993; Bronner et al. 1994; Papadopoulos et al. 1994). mutH homologs have not been identified in these organisms and DNA methylation apparently does not occur in yeast, leaving open the question of how base pair mismatches are repaired so that repair is directed toward the template strand. Interestingly in yeast, four mutS (MSH1, MSH2, MSH3, MSH4; Reenan and Kolodner 1992a; New et al. 1993; Burns et al. 1994) and three mutL (PMS1, MLH1, MLH2; Kramer et al. 1989b; Prolla et al. 1994a) homologs have been identified, each of which shows significant identity at the amino acid level to their bacterial counterparts. Recent genetic and biochemical analysis in yeast suggests that $M S H 2$ is the major nuclear mutS homolog and that two mut $L$ homologs, PMS1 and MLH1, are required for mismatch repair (Reenan and Kolodner 1992a,b; Miret et al. 1993; Alani et al. 1994; Prolla et al. 1994a).

Genetic analysis in yeast revealed that msh2 mutants are defective in the repair of mispaired bases including all single base pair mismatches (Reenan and Kolodner 1992b; Alani et al. 1994). Furthermore, msh2 mutants display an increased spontaneous mutation rate and an increased rate of 2- and 4-bp insertion/deletions at dinucleotide repeat regions (Reenan and Kolodner 1992b; Strand et al. 1993). Nearly identical phenotypes were observed in pms1 and mlh1 mutants, consistent with the idea that MSH2, PMS1, and MLH1 are in the same epistasis group and interact during mismatch repair (Bishop et al. 1987, 1989; Kramer et al. 1989a; Strand et al. 1993; Alani et al. 1994; Prolla et al. 1994a). This idea is supported by recent biochemical studies demonstrating that the Msh2, Pms1, and Mlhl proteins form a complex with a duplex oligonucleotide containing a $\mathrm{G} / \mathrm{T}$ mismatch (Prolla et al. 1994b). A systematic analysis of the fate of insertion/deletion loops has not been performed in Saccharomyces cerevisiae. However, it has been shown that 1-, 2- and 4-nucleotide loop mispairs are repaired efficiently in an MSH2-dependent fashion, 8- to 12-nucleotide loop mispairs are repaired efficiently in a PMS1dependent fashion, and 8- to 12-nucleotide palindromic insertions are repaired efficiently (Bishop and Kolodner 1986; Bishop et al. 1987; Nag and Petes 1991; Alani et al. 1994). In contrast, palindromic insertions $>14$ nucleotides, and 37 and 38 nucleotide loops are repaired at lower levels (Kramer et al. 1989a, Nag and Petes 1991; Manivaskam, S.M. Rosenberg and P.J. Hastings, in prep.).

Until recently, very little was known biochemically about the yeast and mammalian mismatch repair proteins. In humans, an activity was purified several thousand fold that recognizes base pair mismatches with moderate selectivity (Hughes and Jiricny 1992). When fractions containing this activity were incubated with oligonucleotide containing a G/T mismatch and then UV irradiated, polypeptides of molecular mass 160 and $100 \mathrm{kD}$ were shown to specifically cross-link to the oligonucleotide. Protease digestion studies suggested that the $100-\mathrm{kD}$ polypeptide was a proteolytic fragment derived from the larger polypeptide (Hughes and Jiricny 19921. However, subsequent amino acid sequencing analysis revealed that the $100-\mathrm{kD}$ polypeptide corresponds to human Msh2; further analysis of the $160-\mathrm{kD}$ polypeptide has not been reported (Palombo et al. 1994). In yeast, an MSH2-dependent mismatch-binding activity was identified in nuclear extracts that displayed affinities for binding that correlated reasonably well to the efficiency of mismatch repair in vivo; however, these studies did not directly demonstrate that the observed protein-DNA complexes contained Msh2 (Miret et al. 1993). Studies by Chi and Kolodner (1994a) indicated that the $M S H 1$ gene, which is required for mitochondrial DNA metabolism, encodes a protein that recognizes base pair mismatches with affinities that correlate with the repair efficiencies of base pair mismatches observed in $E$. coli. In this report we describe the purification and characterization of the MSH2 gene product and demonstrate that it can recognize G/T mismatches and small insertion mispairs with moderate affinity and palindromic insertion mispairs with higher affinity. These results are interpreted with respect to a model that proposes a mechanistic role for mismatch repair proteins during DNA replication and genetic recombination. 


\section{Results}

Overexpression of Msh2 protein

We initiated our analysis of Msh2 on the basis of previous genetic and biochemical experiments suggesting that Msh2 is the major mismatch recognition protein in S. cerevisiae (Reenan and Kolodner 1992a,b; Miret et al. 1993; Alani et al. 1994). We constructed a $2 \mu$, GAL10 MSH2 overexpression plasmid that allowed for purification of the Msh2 polypeptide by conventional chromatography. pEN11 (Fig. 1A) was constructed by fusing the GAL10 promoter to the predicted initiation codon of the MSH2 gene. This construct was based on a similar GAL10-SEP1 fusion that resulted in induction of the SEP1 protein to $6 \%$ of total soluble protein (Johnson and Kolodner 1991). pEN43, a derivative of pEN11 that contains the 12CA5 epitope tag at amino acid 644 in the MSH2 open reading frame, was constructed to monitor the Msh2 purification by both immunoprecipitation and Western blotting (refer to Materials and methods). The epitope-tagged variant of $M S H 2$ will be referred to as $M S H 2:: C A 5$. An ARS CEN vector that contained the $M S H 2:: C A 5$ gene under the $M S H 2$ promoter was able to fully complement the mutator phenotype of msh2 strains as measured by the canvanine-resistance mutator assay described by Reenan and Kolodner (1992b) (data not shown).

Overexpression of Msh2 was accomplished by first transforming the pEN11 and pEN43 plasmids into BJ5464, a protease-deficient strain, and then inducing the resulting strains using a galactose shift protocol described by Johnson and Kolodner (1991). A 109-kD protein that corresponded to the predicted size of the Msh2 polypeptide (Reenan et al. 1992a) was observed after galactose induction in both BJ5464/pEN1l and BJ5464/ pEN43, and the highest levels of this band were observed after $7 \mathrm{hr}$ postinduction (Fig. 1B). The maximal levels of soluble Msh2 protein observed were estimated to be equivalent to $0.5-1 \%$ of total protein. Immunofluorescence experiments, using the 12CA5 monoclonal antibody and BJ5464/pEN43 strains grown in galactose, revealed that overexpressed Msh2 protein is located in the nucleus (J. Vogel, P. Silver, E. Alani, and R.D. Kolodner, unpubl.). This finding is consistent with the idea that the Msh2 protein is involved in nuclear DNA repair.

Three lines of evidence argue that the induced band is the Msh2 polypeptide. First, the induced band was not observed in BJ5464 cells grown in galactose or in BJ5464/ pEN11 cells grown in glucose. Second, the induced 109$\mathrm{kD}$ polypeptide was specifically immunoprecipitated with 12CA5 antibody from galactose-induced BJ5464/ pEN43 cell extracts (Fig. 1B, lane 3). Third, the Msh2::CA5 protein could be purified using the same chromatographic steps as was used for the Msh2 protein; its purification was also monitored by Western blot using 12CA5 monoclonal antibody (data not shown).

\section{Purification of Msh2}

The Msh2 protein was solubilized by rapid glass bead
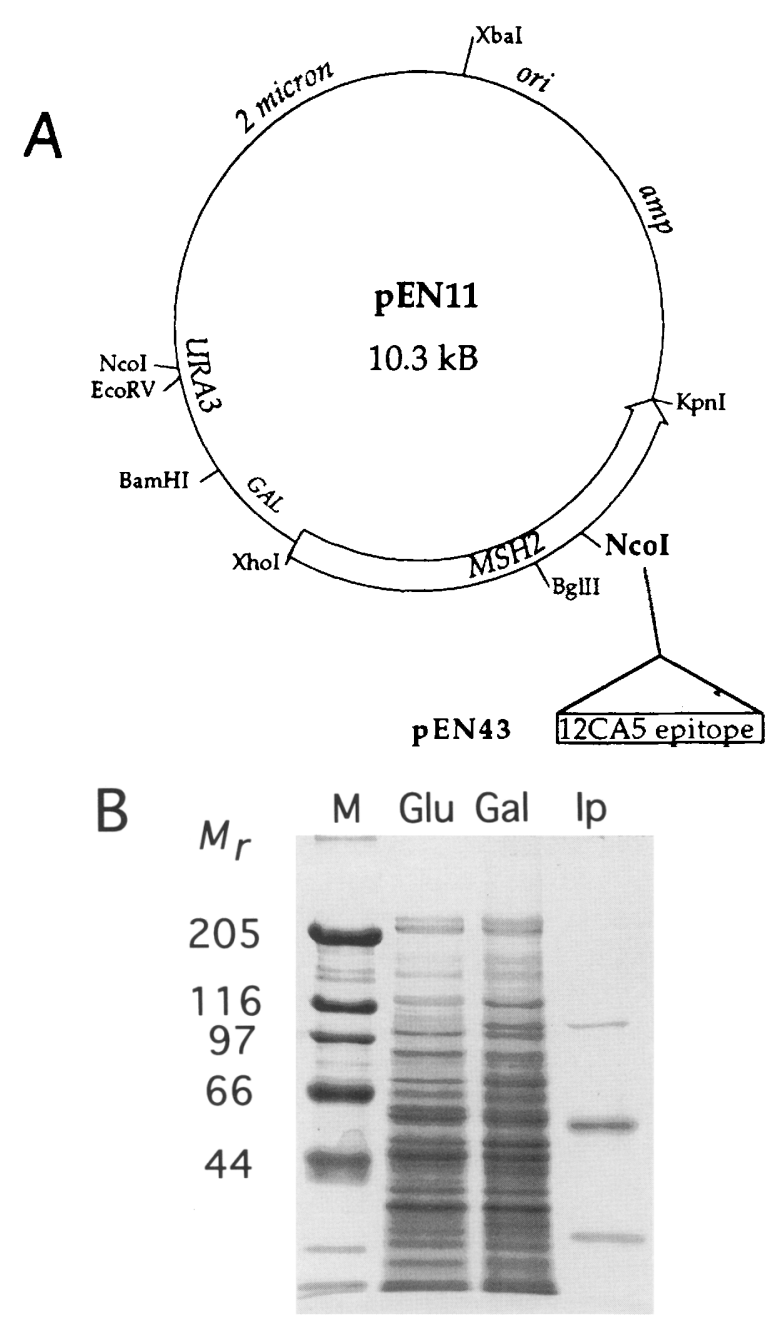

Figure 1. (A) Restriction map of pEN1l, a galactose-inducible MSH2 expression plasmid. The plasmid is drawn to scale. pEN43 is a derivative of pEN11 that contains a 33-bp oligonucleotide insertion at the NcoI site of $M S H 2$. This insertion sequence encodes the epitope sequence YPYDVPDYA that is recognized by mAb 12CA5 (see Materials and methods). (B) A 109. $\mathrm{kD}$ polypeptide corresponding in size to the Msh2 polypeptide is specifically induced in BI5464/pEN11 grown in galactose. Crude extracts (fraction I, Fig. 2) prepared from BJ5464/pEN11 grown in glucose (Glu) and galactose (Gal) were electrophoresed on $10 \%$ SDS-PAGE. The lane labeled Ip contains an aliquot of a $12 \mathrm{CA} 5$ immunoprecipitate of BJ5464/pEN43 grown in galactose (see Materials and methods).

lysis and purified to near homogeneity using conventional chromatographic steps as described in Materials and methods (fraction IV, Fig. 2A). The Msh2 purification was monitored by following the $109-\mathrm{kD}$ induced band in SDS-PAGE and by monitoring mispair-specific binding activity by measuring binding to ${ }^{32} \mathrm{p}$-labeled +14 PAL substrate in the presence or absence of homoduplex and + 14 PAL competitors (Figs. 3 and 4). On average $140 \mu \mathrm{g}$ of Msh2 fraction IV was obtained from 20 grams of BJ5464/pEN11 yeast cells.

Msh2 appeared to be $>90 \%$ pure and did not appear to 

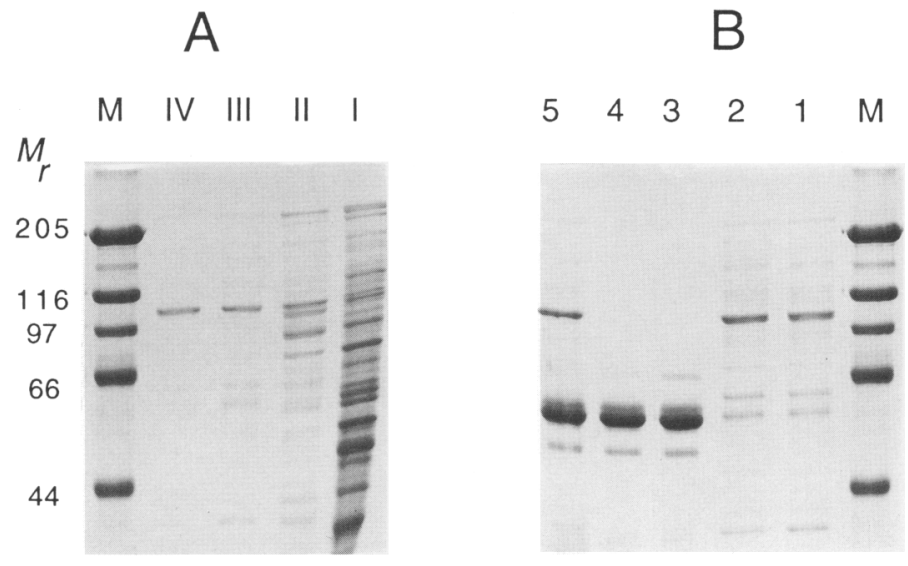

Figure 2. (A) SDS-PAGE analysis of protein fractions from the purification of Msh2. (Fraction I) 14 $\mu \mathrm{g}$ of crude extract; (fraction II) $1.2 \mu \mathrm{g}$ of Msh2-containing fractions eluted from PBE94; (fraction III: $0.74 \mu \mathrm{g}$ of protein eluted from Bio-Rex 70 with $0.5 \mathrm{M}$ $\mathrm{NaCl}$; (fraction IV) $0.36 \mu \mathrm{g}$ of protein eluted from phosphocellulose with $1.0 \mathrm{M} \mathrm{NaCl}$. (M) Molecular weight standards; relative molecular masses are provided. (B) mAb 12CA5 specifically immunoprecipitates Msh2::CA5 protein. Fraction III purified from cell extracts that were induced for the expression of Msh2 and Msh2::CA5 were immunoprecipitated using 12CA5 antibody. (M) Molecular weight standard. (Lane 1) $1.1 \mu \mathrm{g}$ of fraction III derived from B)5464/ pEN1 1 grown in galactose; (lane 2) $1.1 \mu \mathrm{g}$ of fraction III derived from BJ5464/pEN43 grown in galactose; (lane 3) immunoprecipitate of buffer; (lane 4) immunoprecipitate of BJ5464/pEN11 fraction III (equivalent to immunoprecipitation of $2.5 \mu \mathrm{g}$ of fraction III, lane 1 ); (lane 5) immunoprecipitate of BI5464/pEN43 fraction III (equivalent to immunoprecipitation of $2.5 \mu \mathrm{g}$ of fraction III, lane 21 .

contain contaminating Pmsl or Mlhl proteins, consistent with the fact that Msh2 does not interact with these proteins (Prolla et al. 1994b). It was difficult to estimate the fold purification of Msh2 because we were unable to measure accurately Msh2 activity in fraction I. However, the specific activity of Msh2 in fraction II (PBE 94) was

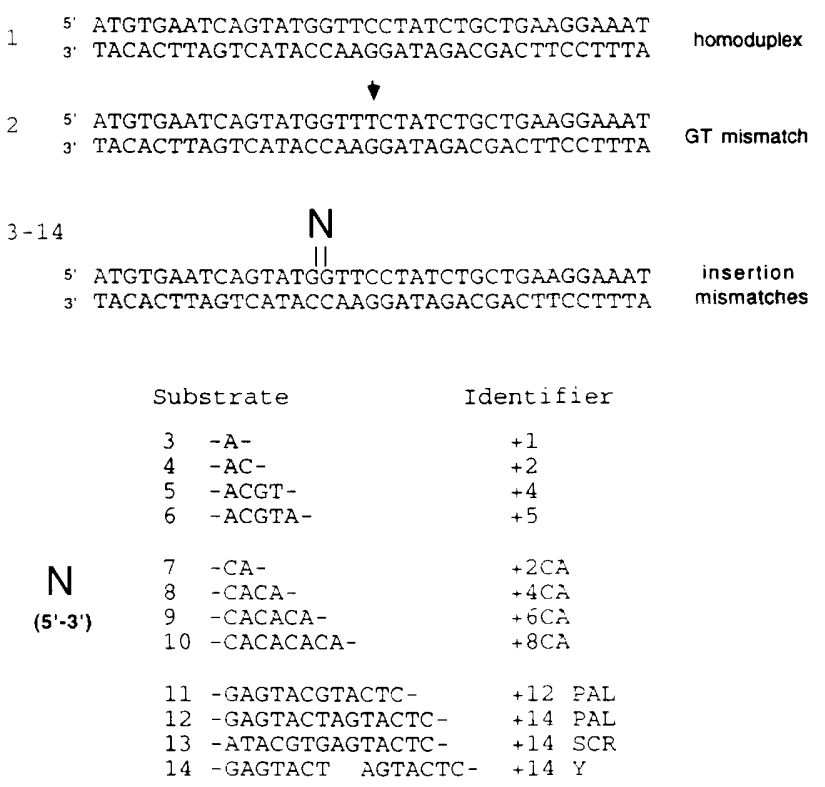

Figure 3. Oligonucleotide duplexes used as substrates for Msh2-binding studies. ${ }^{32} \mathrm{P}$-Labeled homoduplex, +4 and +14 PAL substrates were formed by annealing the common bottom strand labeled at the $5^{\prime}$ end with ${ }^{32} \mathrm{P}$ with the respective unlabeled top strand as described in Materials and methods. Unlabeled competitor duplex oligonucleotides were annealed from single-stranded oligonucleotides using the same annealing procedure. The sequence context of the oligonucleotides is the same as used by Chi and Kolodner (1994a) in their Mshl-binding studies. The sequence of the palindromic insertions is derived from Nag and Petes (1991). increased three- to fourfold by purification through BioRex 70 (fraction III) and phosphocellulose (fraction IV), consistent with the observation that Msh2 was $\sim 20$ $25 \%$ of the protein present in fraction II (see Fig. 2A). The mispair specificity of Msh2 as measured in competition experiments did not change over the last three purification steps.

Five lines of investigation support the conclusion that Msh2 is a mispair-specific DNA-binding protein. First, mispair-specific DNA-binding activity, which was first detected after PBE 94 chromatography, copurified with the $109-\mathrm{kD}$ Msh2 protein species (data not shown). This was the only mispair-binding activity observed during the purification of Msh2. Second, purification of both the $109-\mathrm{kD}$ Msh2 species and the mispair-binding activity required galactose induction of BJ5464/pEN11. Third, there were no contaminating protein species present in Msh2 fraction IV that could account for the stoichiometery of Msh2 binding to mispair-containing DNA substrates (saturation of binding occurred at four Msh2 monomers per oligonucleotide duplex; Fig. 4). Fourth, the purified epitope-tagged Msh2 protein displayed mispair-binding properties similar to the native Msh2 protein (Table 1). Fifth, epitope-tagged Msh2 protein could be immunoprecipitated from crude extracts and the immunoprecipitated Msh2 protein displayed similar mispair-binding properties to the native Msh2 protein. Native (nonepitope-tagged) Msh2 protein could not be immunoprecipitated with mAb 12CA5 ; furthermore, no significant DNA-binding activity could be detected in immunoprecipitates derived from BJ5464/pEN11 galactose-induced extracts (Table 1, Fig. 2B).

\section{Requirements for binding of Msh2 to duplex oligonucleotides}

Initially, we used both gel retardation and filter-binding assays to survey $\mathrm{Msh} 2$ protein for its ability to bind to duplex oligonucleotides containing mispaired bases. Us- 
A

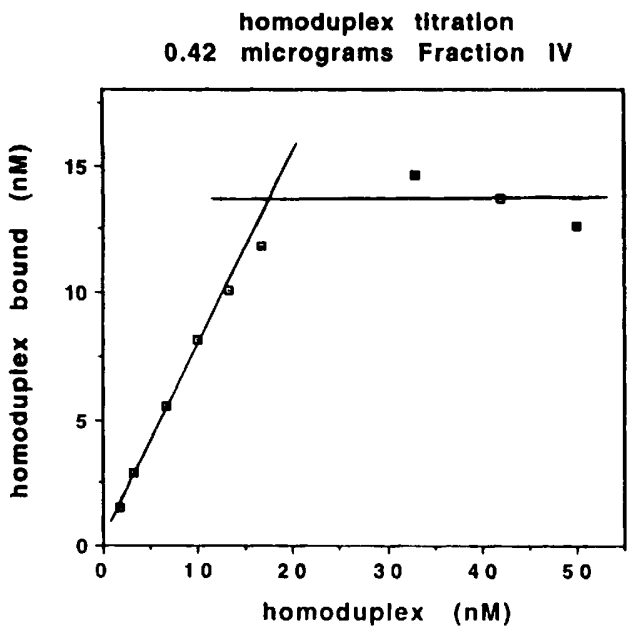

C

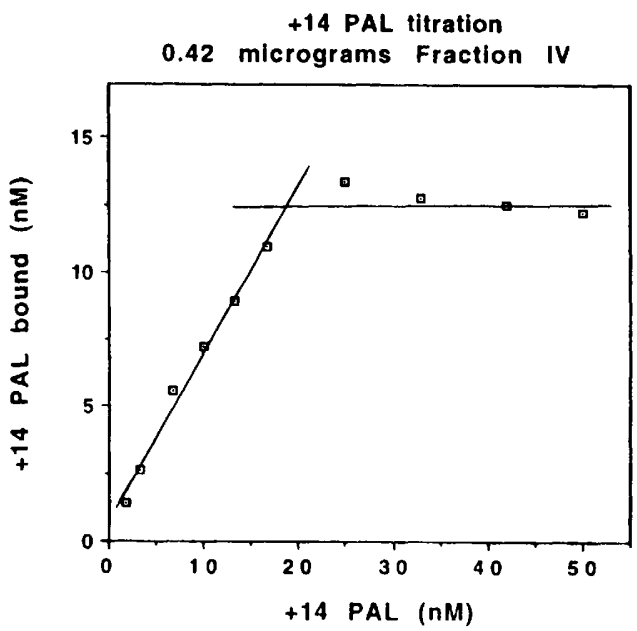

B

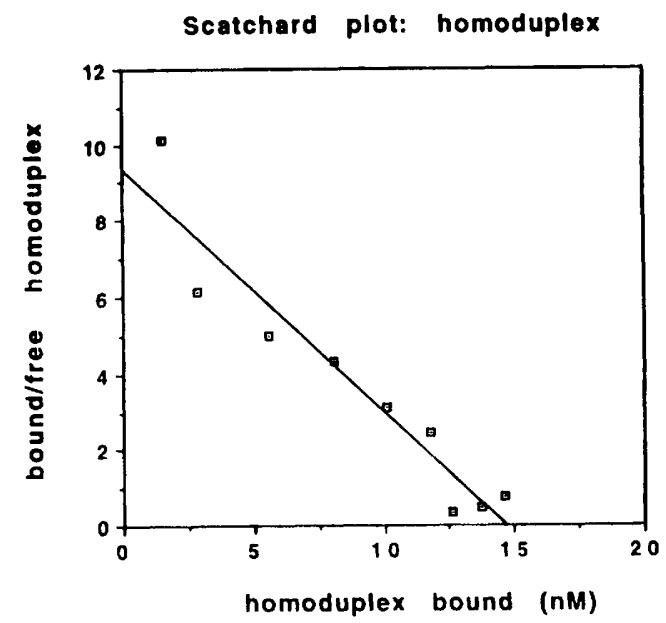

D

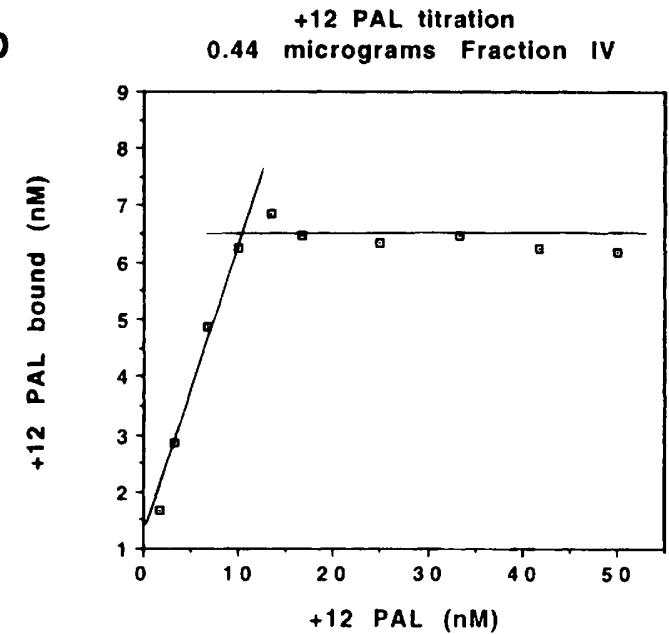

Figure 4. Binding of Msh2 to homoduplex and $+14 \mathrm{PAL}$ substrates. Incubation and filter-binding conditions are described in Materials and methods. Titrations were performed in 60- $\mu$ l reactions containing $25 \mathrm{~mm}$ Tris (pH 7.6), 0.1 mM DTT, 0.01 mM EDTA, $40 \mu \mathrm{g} / \mathrm{ml}$ of BSA, and the indicated amount of Msh2 fraction IV. In A (homoduplex), $C(+14$ PAL), and D (+12 PAL) the saturation point was taken as the intersection of the biphasic curves; the initial slope in each experiment reflects subsaturating levels of oligonucleotides binding to Msh2 and the final slope indicates that saturation binding had been reached. $(B)$ Data from the titrations with homoduplex substrate are presented in a Scatchard plot (described in Cantor and Schimmel 1980). The slope of the curve is equivalent to the $-1 / K_{\mathrm{d}}$ and the $K_{\mathrm{d}}$ was determined to be $1.7 \mathrm{~nm}$.

ing gel retardation assays, we were able to develop conditions under which Msh2 formed specific complexes with oligonucleotides containing a variety of single base mispairs, insertion mispairs, and palindromic insertion mispairs, but did not form significant levels of complex with homoduplex control substrates (data not shown). We found gel retardation assays unsuitable for quantitative analysis of the binding properties of Msh2. This was because poly $[\mathrm{d}(\mathrm{I}-\mathrm{C})]$ had to be included in the reactions to observe discrete complexes and because the immediate analysis of each sample by electrophoresis made it difficult to perform time course experiments. Subsequent experiments were performed using filter-binding assays.
We analyzed the DNA-binding activity of Msh2 under a variety of conditions using two filter-binding assays. The first assay measured the binding of $\mathrm{Msh} 2$ to ${ }^{32} \mathrm{P}$ labeled + $12 \mathrm{PAL},+14 \mathrm{PAL}$, +5, and homoduplex substrates (see Fig. 3). The second assay measured substrate specificity by measuring the binding of $\mathrm{Msh} 2$ to ${ }^{32} \mathrm{P}$-labeled $+14 \mathrm{PAL}$ and +5 substrates in the presence or absence of unlabeled homoduplex, +5 , and +14 PAL competitors (Table 1). In the first assay, maximal binding was observed by $5 \mathrm{~min}$ of incubation and the extent of binding did not change significantly with longer incubation periods of $\leqslant 8 \mathrm{hr}$. The addition of ATP and GTP $(0.1-1.0 \mathrm{~mm})$, glycerol $(10 \% \mathrm{vol} / \mathrm{vol})$, ethylene glycol $(10 \% \mathrm{vol} / \mathrm{vol})$, and storage of $\mathrm{Msh} 2$ at $-70^{\circ} \mathrm{C}$ did not 
Table 1. Msh2 and Msh2::CA5 protein display similar binding specificity

\begin{tabular}{|c|c|c|c|c|}
\hline & \multirow{2}{*}{$\begin{array}{l}\text { pmoles + } 14 \text { PAL bound/ } \\
\mu g \text { Msh } 2 \text { preparation }\end{array}$} & \multicolumn{3}{|c|}{$\begin{array}{c}\text { Specificity ratio }^{\mathbf{a}} \\
{[\text { competitor concentration }(\mathrm{nM})]}\end{array}$} \\
\hline & & 333 & 625 & 1250 \\
\hline \multicolumn{5}{|l|}{ Chromatography } \\
\hline BJ5464/pEN 1 l, fraction III & 0.58 & 2.7 & & \\
\hline BJ5464/pEN43, fraction III & 0.57 & 3.0 & & \\
\hline \multicolumn{5}{|l|}{ Immunoprecipitation } \\
\hline BJ5464/pEN43 (Msh2::CA5) & $0.39^{\mathrm{b}}$ & & 3.8 & 5.5 \\
\hline BI5464/pEN 11 (Msh2) & N.D. & & N.A. & N.A. \\
\hline
\end{tabular}

Fraction III (Bio-Rex 70 fraction; see Fig. 2 for details) of Msh2 and Msh2::CA5 were assayed for binding to homoduplex and the +14 PAL substrate as described in Materials and Methods. (N.D.) Not detected. (N.A.) Not applicable.

${ }^{a}$ The specificity ratio is an indicator of the binding specificity of each fraction for the +14 PAL substrate. This ratio was calculated as the amount of ${ }^{32} \mathrm{P}$-labeled +14 PAL substrate bound (initial concentration $=11.7 \mathrm{nM}$ ) by Msh2 in reactions containing the indicated amount of unlabeled homoduplex competitor divided by the amount bound in reactions containing the same amount of unlabelled + 14 PAL competitor.

bThe initial immunoprecipitation reactions involving BJ5464/pEN43 and BJ5464/pEN11 contained the same amount of extract and were processed in identical fashion.

significantly affect either substrate binding or specificity. Finally, Msh2 binding did not require divalent cations and $\mathrm{NaCl}$ concentrations $>100 \mathrm{~mm}$ were inhibitory. The overall level of binding of Msh2 to substrate did not change significantly as $\mathrm{MgCl}_{2}$ was included in binding reactions over a range of concentrations from 0 to $10 \mathrm{~mm}$. However, a gradual loss in specificity was observed, and at $10 \mathrm{mM} \mathrm{MgCl} \mathrm{Msh}_{2}$ showed no ability to distinguish between homoduplex and mismatched substrates.

\section{Msh2 displays selectivity to duplex oligonucleotides containing loops, palindromic insertions, and a G/T mismatch}

A series of oligonucleotides were synthesized to measure the affinity of binding of Msh2 to different ${ }^{32} \mathrm{P}$-labeled duplex oligonucleotide substrates in the presence or absence of unlabelled competitors. The sequence context of these substrates is identical to that used by Chi and Kolodner (1994a) in their studies of Mshl (see Fig. 3). We synthesized a series of oligonucleotides containing single base pair mismatches at bp 15 and 19 /counting from $5^{\prime}$ to $3^{\prime}$, top strand) and insertion mismatches at bp 15 in the 37-bp duplex oligonucleotide (see Fig. 3). The insertion substrates ranged from those that are well repaired in yeast $(1,2,4,8$, and +12 PAL nucleotide insertions), to several with unknown repair efficiency $15-, 6-$, and 14-nucleotide insertions), to one that is repaired with low but significant frequency $1+14$ PAL nucleotide insertion). Similar-sized duplex oligonucleotides containing single base pair mismatches in three different sequence contexts were also synthesized. We will present the information on these substrates elsewhere.

To measure the binding of Msh2 for homoduplex oligonucleotide, a constant amount of $\mathrm{Msh} 2$ was incubated in the presence of increasing amounts of homoduplex substrate under conditions (see Fig. 7, below, for an analysis of the stability of Msh2-DNA complexes) where equilibrium binding was achieved (substrate 1, Fig. 3). As shown in Figure 4A, binding of Msh2 to homoduplex was saturating at a stoichiometry of 4.4 pmoles of Msh2 per pmole of oligonucleotide (assuming a molecular mass of $109 \mathrm{kD}$ and that fraction IV is $100 \%$ pure). A similar stoichiometry was observed for binding to the +5 /data not shown), + $12 \mathrm{PAL}$, and the $+14 \mathrm{PAL}$ oligonucleotide (Fig. 4C,D). The data obtained for binding of Msh2 to homoduplex was replotted as a Scatchard plot to determine the $K_{\mathrm{d}}$ of binding (Fig. 4B). The $K_{\mathrm{d}}$ for binding to homoduplex was determined to be $1.7 \mathrm{nM}$; this value is $\sim 10$ - to 30-fold lower than was observed for MutS binding to 120-bp oligonucleotides containing $G / T, A / G$, and A/C mismatches, and $\sim 200$ times lower than for MutS binding to a 143-bp oligonucleotide containing a $\mathrm{C} / \mathrm{C}$ mismatch (Su and Modrich 1986; Su et al. 1988). As described below, we could not determine the $K_{\mathrm{d}}$ for the $+12 \mathrm{PAL},+14 \mathrm{PAL}$, and other substrates containing mispaired bases because it was not possible to achieve equilibrium-binding conditions due to the complex mode of binding of Msh2 to mispair containing substrates and the stability of Msh2 mispair complexes. For this reason, the titration studies performed in Fig. 4C,D reflect primarily the on-rate of binding and not equilibrium binding.

To determine if Msh2 specifically recognizes mispaired bases we performed the competition assays shown in Figure 5 under conditions where Msh2 was incubated with stoichiometric amounts of either ${ }^{32} \mathrm{P}$-labeled +14 PAL or ${ }^{32} \mathrm{P}$-labeled +4 substrate $(4.4$ pmoles of Msh2 per pmole of oligonucleotide substrate; Fig. 4) plus varying amounts of unlabeled competitor. Theoretical and experimental considerations have demonstrated that the discrimination between two competitors can be determined by measuring the maximal horizontal separation between the binding curves resulting from such titrations (Chi and Kolodner 1994a). This measurement is best made at the maximum concentration of competitor that 
A

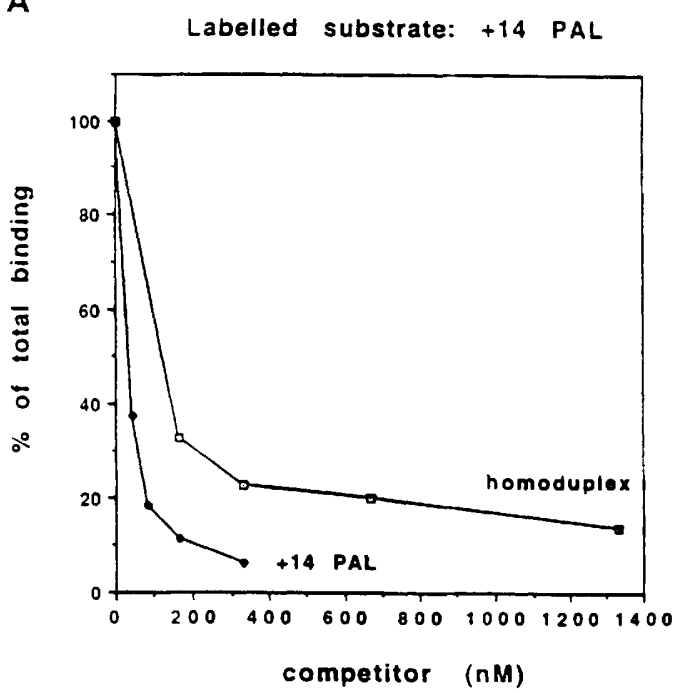

C

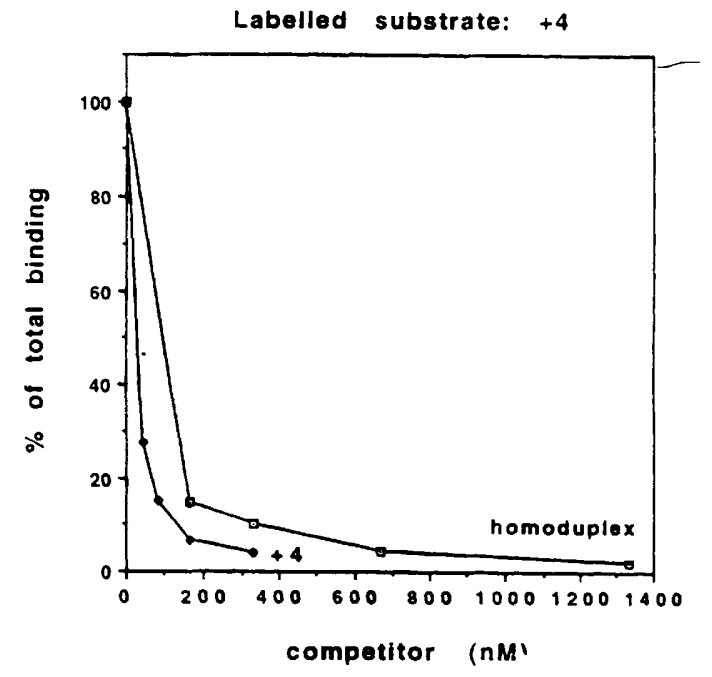

B

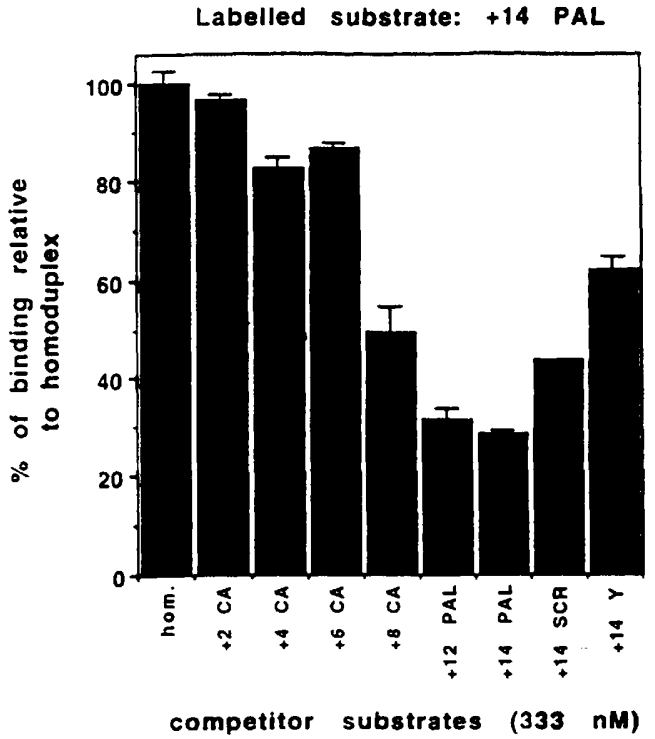

D

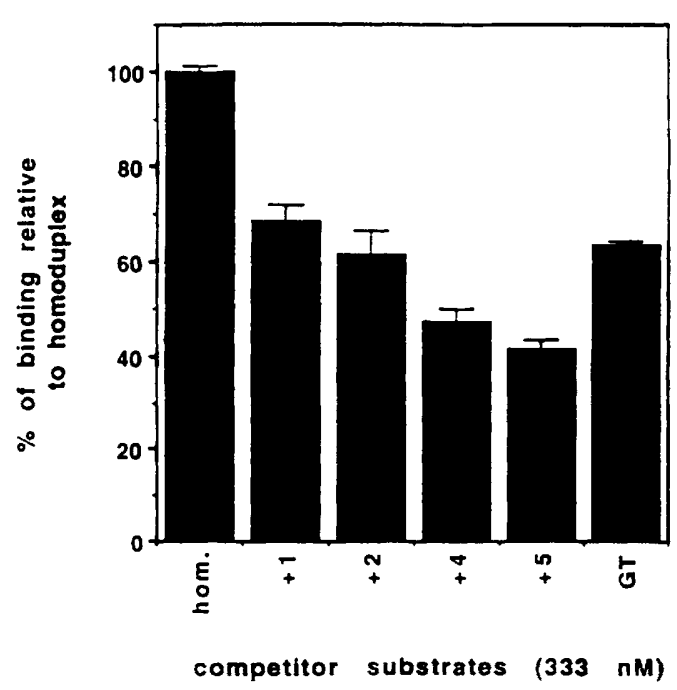

Figure 5. Msh2 protein binds specifically to duplex oligonucleotides containing loops, palindromic insertions, and G/T mismatches. Binding reactions were performed at $30^{\circ} \mathrm{C}$ in duplicate $60-\mu$ l reactions containing $25 \mathrm{~mm}$ Tris (pH 7.6), $0.1 \mathrm{~mm}$ DTT, $0.01 \mathrm{~mm}$ EDTA, $40 \mu \mathrm{g} / \mathrm{ml}$ of BSA, $0.42 \mu \mathrm{g}$ of Msh2 fraction IV, $11.7 \mathrm{~nm}{ }^{32} \mathrm{P}$-labeled substrate, and the indicated amount of unlabeled competitor substrates. After incubation for $15 \mathrm{~min}$, the amount of ${ }^{32} \mathrm{P}$-labeled substrate that remained bound to Msh2 was measured by filter binding. The duplicates were averaged and the degree of error is presented. $+14 \mathrm{PAL}$ was the ${ }^{32} \mathrm{P}$-labeled substrate in $A$ and $B ;+4$ was the ${ }^{32}$ P-labeled substrate in $C$ and $D$. In $A$ and $C$ the percent of binding was normalized to a control reaction in which no competitor was present. In $B$ and $D$ a single concentration ( $333 \mathrm{nM}$ ) of the indicated unlabeled competitors (refer to Fig. 2 ) was used and the percent of binding was normalized to reactions that contained homoduplex as competitor.

still allows accurate determination of substrate binding because the horizontal separation between the binding curves is constant at high degrees of competition. As shown in Figure 5A, 13-fold higher levels of homoduplex competitor were required to achieve the same degree of competition for the ${ }^{32} \mathrm{P}$-labeled $+14 \mathrm{PAL}$ substrate as was observed with the +14 PAL competitor when high levels of competition are achieved. Single-stranded olig- onucleotides, specifically the top and bottom strands of +14 PAL, showed no competition when present in the concentration ranges of competitors used in the analysis shown in Figure 5 (data not shown). On the basis of the competition titrations displayed in Figure $5 \mathrm{~A}$, we chose a standard competitor concentration of $333 \mathrm{nM}$ and compared the ability of various substrates to compete for the ${ }^{32}$ P-labeled + 14 PAL substrate (Fig. 5B). At this concen- 
tration, unlabeled homoduplex and + 14 PAL substrates showed the greatest difference in their ability to compete for the ${ }^{32}$ P-labeled +14 PAL substrate. Such experiments using a fixed competitor concentration allow a relative ranking of the effectiveness of each competitor but do not allow determination of the absolute discrimination for binding to each competitor. A general trend observed was that the effectiveness of the competitor was directly proportional to the size of the insertion mispair present in the competitor $1+14 \mathrm{SCR}>+8>+4$, $+6>+2)$. The palindromic substrates $(+12 \mathrm{PAL},+14$ PAL/ were more effective competitors than nonpalindromic insertions of similar size. Furthermore, removing bases that were predicted to form an unpaired singlestranded loop at the tip of the palindrome produced a less effective competitor $(+14 \mathrm{Y}$ substrate). This suggests that Msh2 may recognize the $+14 \mathrm{PAL}$ substrate in two different ways: (1) by recognizing the unpaired bases at the tip of the extruded insertion, and (2) by recognizing the structure at the base of the extruded insertion.

We then performed competition experiments using a +4 insertion substrate because 4 -nucleotide insertion and deletion mispairs are well repaired in yeast and their repair is dependent on the $\mathrm{MSH} 2$ gene product. As shown in Figure 5C, higher levels of homoduplex oligonucleotide were required to achieve the same degree of competition for the ${ }^{32} \mathrm{P}$-labeled +4 substrate than was observed with the +4 competitor. On the basis of the titrations in Figure 5C we chose a competitor concentration of $333 \mathrm{~nm}$ to compare the ability of various substrates to compete for the ${ }^{32}$ P-labeled +4 insertion substrate (Fig. 5D). At this concentration, unlabeled homoduplex and +4 substrates showed the greatest difference in their ability to compete for the ${ }^{32}$ P-labeled +4 substrate. Similar to the results obtained with the $+14 \mathrm{PAL}$ substrate, there was a general trend in that the size of the insertion was directly proportional to the effectiveness of the competitor $(+5>+4>+2>+1)$. Furthermore, we observed that an oligonucleotide containing a $G / T$ mismatch was a significantly better competitor than the homoduplex competitor, indicating that Msh2 recognizes single base mispairs as well as insertion mispairs. These experiments indicate that Msh2 can form complexes with both homoduplex substrates and substrates containing a variety of mispaired bases. They also indicate that Msh2 recognizes mispaired bases although they do not allow an exact determination of the binding affinity for mispairs.

To further investigate the specificity of Msh2 for single base pair mismatches and to discern whether the specificity of Msh2 for mismatched substrates was dependent on substrate length, we synthesized a 100-bp oligonucleotide containing a single $\mathrm{G} / \mathrm{T}$ mismatch at bp 50 (Fig. 6). The sequence of this oligonucleotide corresponds to bp 638-737 in the HIS4 coding region (Donahue et al. 1982). As shown in Figure 6, Msh2 was incubated with stoichiometric amounts of ${ }^{32} \mathrm{P}$-labeled G/T mismatch substrate (15 pmoles of Msh2 per pmole of 100-bp oligonucleotide) plus varying amounts of unlabeled $G / T$ mismatch and homoduplex $(A / T)$ competitor.

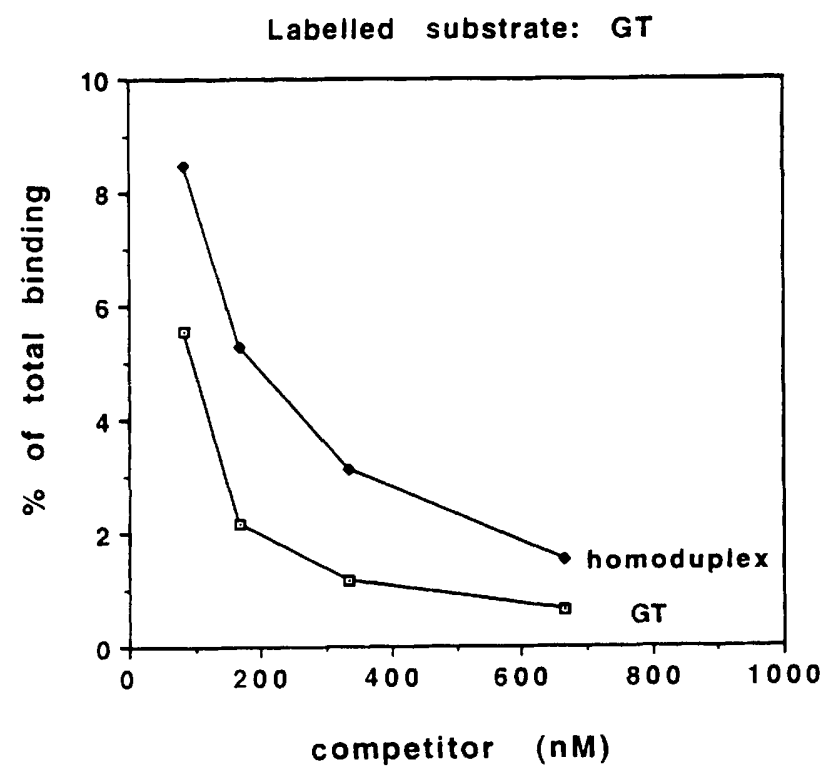

Figure 6. Specificity of Msh2 for a 100-bp duplex oligonuclotide containing a $\mathrm{G} / \mathrm{T}$ mismatch. Binding reactions were performed at $30^{\circ} \mathrm{C}$ in $60-\mu l$ reactions containing $25 \mathrm{~mm}$ Tris $1 \mathrm{pH}$ 7.61, $0.1 \mathrm{mM}$ DTT, $0.01 \mathrm{mM}$ EDTA, $40 \mu \mathrm{g} / \mathrm{ml} \mathrm{BSA}, 0.42 \mu \mathrm{g}$ of Msh2 fraction IV, $5.5 \mathrm{nM}{ }^{32} \mathrm{P}$-labeled G/T substrate, and the indicated amount of unlabeled competitor substrates. After incubation for $15 \mathrm{~min}$, the amount of ${ }^{32} \mathrm{p}$-labeled substrate that remained bound to Msh2 was measured by filter binding. The percent of binding was normalized to a control reaction in which no competitor was present.

As shown in Figure 6, approximately three- to fourfold higher levels of homoduplex competitor were required to achieved the same degree of competition for the ${ }^{32} \mathrm{P}$ labeled $G / T$ substrate as was observed with the G/T competitor.

\section{Dissociation of the Msh2-oligonucleotide complex is biphasic}

To obtain additional insight into the nature of the Msh2 mispair complexes, we formed complexes between Msh2 and either the homoduplex or the +12 PAL substrate, added an excess of unlabeled competitor, and then measured the stability of the original Msh2-DNA complexes over time. The +12 PAL substrate was chosen for this study because Msh2 bound to it with high specificity compared to the homoduplex substrate and because this substrate is well repaired in vivo. In the absence of competitor, there was little difference in the overall binding of Msh2 to the ${ }^{32} \mathrm{P}$-labeled $+12 \mathrm{PAL}$ versus the ${ }^{32} \mathrm{P}$-labeled homoduplex substrate. However, in the presence of competitor, both complexes exhibited a biphasic decay indicating the presence of two types of complexes: (1) an unstable complex $\left(t_{1 / 2} \sim 1 \mathrm{~min}\right.$ for the homoduplex, $t_{1 / 2} \sim 2$ min for the +12 PAL substrate) (Fig. 7) and (2) a stable $\left(t_{1 / 2} \sim 1.5 \mathrm{hr}\right.$ for homoduplex, $t_{1 / 2}>6 \mathrm{hr}$ for +12 PAL) (Fig. 7). A much greater proportion of the complexes formed with the homoduplex substrate were of 


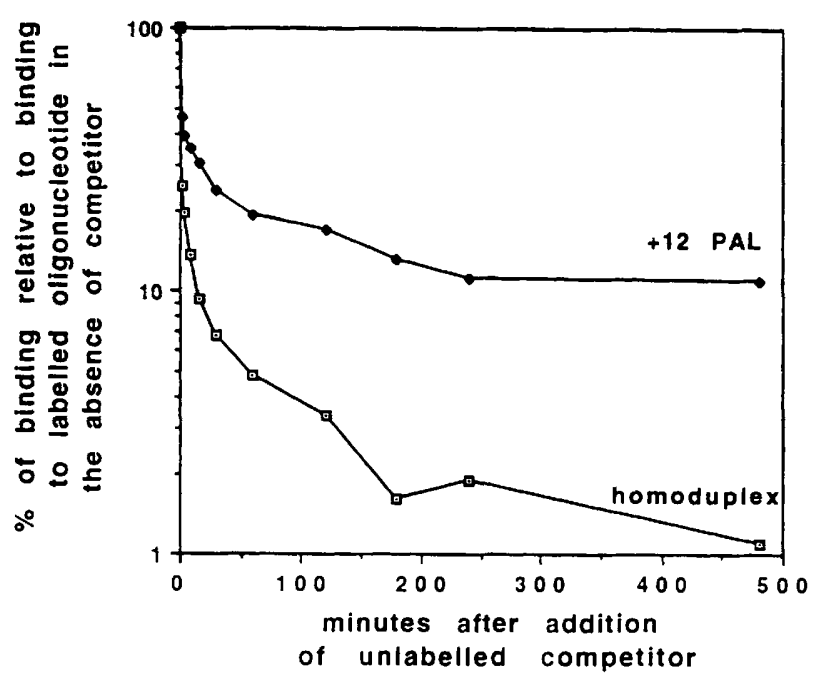

Figure 7. Competition studies revealed slow and fast off rates for Msh2 binding to homoduplex and + 12 PAL substrates. Binding was performed in $120-\mu \mathrm{l}$ reactions containing $25 \mathrm{mM}$ Tris (pH 7.6), $0.1 \mathrm{~mm}$ DTT, $0.01 \mathrm{~mm}$ EDTA, $40 \mu \mathrm{g} / \mathrm{ml}$ of BSA, $0.84 \mu \mathrm{g}$ of Msh2 fraction IV, and $11.7 \mathrm{nM}^{32} \mathrm{P}$-labeled homoduplex or 12 PAL substrate. After incubation for $15 \mathrm{~min}$ at $30^{\circ} \mathrm{C}$, a 140 -fold excess of the respective unlabeled substrate was added to prevent subsequent binding of Msh2 to the labeled substrate, and at various time points an aliquot was removed and the amount of ${ }^{32} \mathrm{P}$-labeled substrate that remained bound to Msh2 was measured by filter binding. The percent binding is normalized to a control reaction in which unlabeled competitor was not added to the respective ${ }^{32} \mathrm{P}$-labeled oligonucleotide-Msh2 complex. Background levels of binding were observed for both homoduplex and +12 PAL reactions when unlabeled competitor was initially included in the binding reaction.

the unstable type compared to the complexes formed with the mispair-containing substrate. After $\sim 100 \mathrm{~min}$ the percent of binding in the homoduplex reaction reached the control value observed when competitor was added before the addition of Msh2 indicating that all of the complex with the homoduplex ultimately disassociated. In contrast with this, even after an 8 -hr incubation with competitor, nearly $15 \%$ of the +12 PAL substrate was present in stable complex (Fig. 7). Similar biphasic decay to yield a significant proportion of stable, mispairdependent complexes has been observed for complexes between Mshl and single base mispair-containing substrates (Chi and Kolodner 1994a).

On the basis of the experiments presented in Figure 7, we hypothesize that Msh2 binds initially to DNA and forms an unstable and nonspecific complex that rapidly dissociates allowing a new cycle of binding to occur. Some proportion of the complexes formed are stable and the formation of these stable complexes requires the presence of a mispaired base in the substrate. The result of these interactions is a partitioning between unstable and stable complexes. A prediction of this model is that the partitioning into stable complexes would increase over time. To test this idea, we performed an experiment in which a stoichiometric amount of ${ }^{32} \mathrm{P}$-labeled +12
PAL-Msh2 complex 14.4 molecules of Msh2 to 1 molecule of +12 PAL) was incubated in standard binding buffer for 5-120 min. At the specified time, a 70 -fold excess of +12 PAL substrate was added and the samples were then incubated for an additional $120 \mathrm{~min}$. A 120 min challenge time was chosen because under these conditions all of the unstable complexes have dissociated and reassociated with unlabeled competitor, whereas little if any of the stable complexes have disassociated (Fig. 7). As shown in Figure 8 , the percent of ${ }^{32}$ P-labeled +14 PAL-Msh2 complex that is insensitive to competitor progressively increased from $5 \%$ after a 5 -min preincubation to $27 \%$ after a 120 -min preincubation, indicating that partitioning between unstable and stable complexes occurs. The overall amount of the ${ }^{32}$ p-labeled +12 PALMsh2 complex incubated in the absence of competitor did not change significantly thoughout the entire course of the experiment.

\section{Discussion}

In this paper we describe the purification of the $S$. cerevisiae Msh2 protein and demonstrate that it can bind specifically to duplex oligonucleotides containing loop insertions, palindromic insertions, and G/T mismatches. Msh2 displayed the highest specificity to pal-

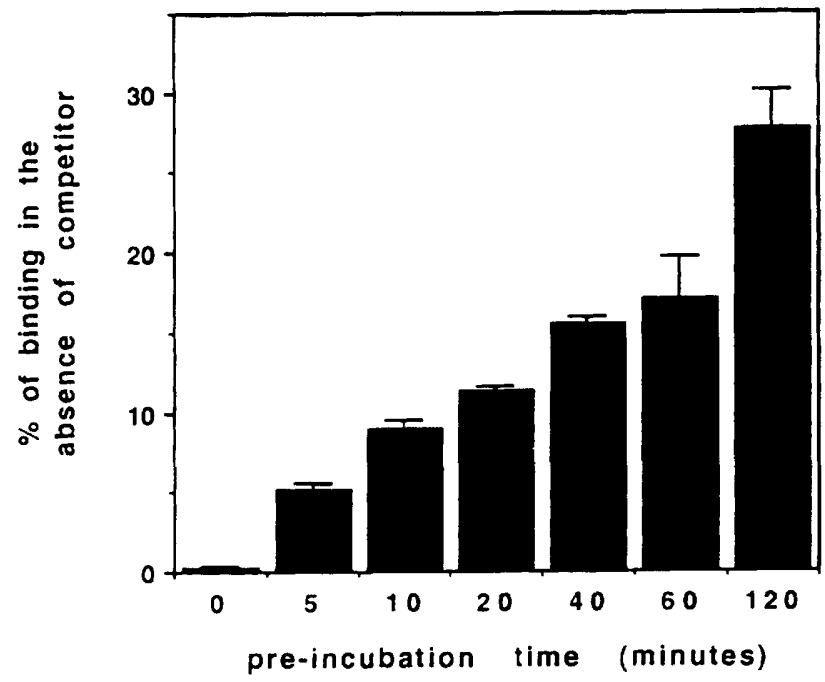

Figure 8. The formation of stable Msh2-+12 PAL complexes results in the partition of Msh2 onto mispair-containing substrates. Binding was performed at $30^{\circ} \mathrm{C}$ in a $120-\mu l$ reaction containing $25 \mathrm{~mm}$ Tris $(\mathrm{pH} 7.6), 0.1 \mathrm{~mm}$ DTT, $0.01 \mathrm{~mm}$ EDTA, 40 $\mu \mathrm{g} / \mathrm{ml}$ of BSA, $0.84 \mu \mathrm{g}$ of $\mathrm{Msh} 2$ fraction IV, and $23.3 \mathrm{nM}{ }^{32} \mathrm{P}$ labeled + 12 PAL substrate. At the indicated times, $10-\mu \mathrm{l}$ aliquots were removed and added to tubes containing a 70-fold excess of unlabeled, +12 PAL substrate. Samples were then incubated at $30^{\circ} \mathrm{C}$ for an additional $120 \mathrm{~min}$, after which the amount of ${ }^{32} \mathrm{P}$-labeled +12 PAL substrate that remained bound to Msh2 as stable complex was measured by filter binding. Data are expressed as the percent of oligonucleotide bound compared to a control reaction in which no competitor was added. Duplicate reactions were performed, the results were averaged, and the degree of error is presented. 
indromic insertions and displayed increasing specificity to loop insertions as the loop size was increased from 1 to 14 nucleotides. DNA-binding titrations performed in the absence of competitor indicated that Msh2 bound to homoduplex, loop insertion, and palindromic substrates with similar affinity; the selectivity of Msh2 for mismatch-containing substrates became apparent in competition studies and in off-rate studies. Our analysis clearly shows that Msh2 exhibits at least two modes of binding to DNA: (1) the formation of nonspecific, unstable complexes and (2) the formation of specific, stable complexes that are dependent on the presence of mispaired bases in the DNA substrate. Similar binding modes have also been demonstrated recently for the binding of Mshl to DNA (Chi and Kolodner 1994a).

Although we were able to demonstrate that purified Msh2 protein binds with moderate specificity to mismatched duplex oligonucleotides, Msh2 clearly has a higher affinity for loop insertion and palindromic insertion mispairs than single base mispairs. For example, the specificity of Msh2 binding to duplex oligonucleotides containing loop insertions increases as the loop size increases. This result is consistent with the observations that 8-and 12-nucleotide loop insertions are repaired efficiently in yeast in a PMS1-dependent fashion (Bishop and Kolodner 1986; Bishop et al. 1987), and other small insertion mispairs are known to be repaired in a $\mathrm{MSH2}$-, PMS1-, and MLH1-dependent fashion (Reenan and Kolodner 1992b; Alani et al. 1994; Prolla et al. 1994a). In addition, the +12 PAL insertion studied here is also known to be repaired efficiently in vivo ( $\mathrm{Nag}$ and Petes 1991). Furthermore, Umar et al. (1994a) recently showed that human cell extracts were capable of repairing $\leqslant 5$ nucleotide loop insertions in a hMSH2-dependent manner, and Fishel et al. (1994), using the substrates described here that we provided for their studies, showed that human Msh2 has a higher apparent specificity for loop insertion mispairs compared to single base mispairs, confirming the results presented here and indicating that this is a general property of Msh2. This higher affinity of Msh2 for insertion mispairs is in agreement with the observation that msh2, pms1, and mlh1 mutations cause a greater mutator phenotype in assays that measure mutations in repeat sequences where mutagenesis involves the formation of insertion loop mispairs compared with forward mutation rate assays where mutations involving the formation of single base mispairs can be detected (Reenan and Kolodner 1992b; Strand et al. 1993; Alani et al. 1994; Prolla et al. 1994a). This appears to be in contrast to the properties of the $E$. coli MutS protein that does not appear to show higher binding to insertion loop mispairs compared to single base mispairs and binds poorly to loop insertions $>4$ nucleotides (Parker and Marinus 1992). This property is reflected in the modest effect of $E$. coli mut $S$ mutations in mutator assays that measure the accumulation of mutations in repeat sequences where mutagenesis involved the formation of insertion loop mispairs (Levinson and Gutman 1987). In summary, these observations indicate that the yeast and human Msh2 proteins have different mispair recognition properties compared to E. coli MutS, and that these properties are reflected in the in vivo activity of mismatch repair in these organisms.

An interesting feature of our data is that Msh2 displayed a high specificity for a palindromic substrate of 14 nucleotides that is poorly repaired in vivo ( Nag and Petes 1991). Although it was reported initially that the specificity of MutS for mispaired bases paralleled the efficiency of repair of these mispaired bases in vivo, it should be noted that MutS binding to mismatched oligonucleotides does not always correlate with the repair efficiencies observed in vivo. For example, an oligonucleotide containing an $\mathrm{A} / \mathrm{C}$ mismatch was not recognized by MutS in vitro, whereas the mismatch present in the same sequence context was well repaired in vivo (Jiricny et al. 1988). These observations suggest that mispair binding may not be the only property required for productive mispair recognition in vivo. Studies of mismatch repair in $E$. coli have demonstrated that the sequence context of a mispaired base can significantly influence the frequency of repair, suggesting a sequence context effect on mismatch recognition (Jones and Radman 1987). These observations indicated that a detailed analysis of substrate structure will be required to understand fully how proteins like Msh2 recognize mismatched bases in DNA.

The rather modest apparent selectivity of Msh2 for mispaired bases in vitro seems in contrast to the efficient repair of mispaired bases in vivo. Even the somewhat greater apparent specificity of proteins like MutS and Mshl seems insufficient to account for mismatch repair given the high ratio of complementary to mismatched base pairs that must be present in a cell after DNA replication but before postreplicative mismatch repair (Modrich 1991). At present we do not understand how the structure of substrates containing single base pair mismatches affects recognition by Msh2 protein or how much the model substrates used to study recognition in vitro differ from the in vivo substrates. One parameter appears to be substrate size; in our studies a G/T mismatch present in a 100-bp oligonucleotide showed higher apparent Msh2 affinity than a G/T mismatch present in a 37-bp oligonucleotide.

The mismatch repair proteins isolated from bacteria, yeast, and humans all show only a modest selectivity for DNA-containing base pair mismatches. Our results indicate that Msh2 can bind specifically to a single base mispair; however, the selectivity for such substrates is low. The observation that Msh2 forms two types of complexes with DNA provides an explanation for how such a modest apparent selectivity could result in efficient repair. The first complex is unstable and is formed when Msh2 binds to homoduplex DNA; this complex may not be competent for subsequent steps in mismatch repair. The second type of complex is stable and is formed when Msh2 binds to DNA-containing mismatched bases. The stability of this complex suggests that Msh2 undergoes a conformational change when it is bound to substrates containing mispaired bases that results in increased stability of the complex and provides a recognition signal 
for interaction with mismatch repair proteins involved in subsequent steps. Such a mechanism could amplify the selectivity of Msh2 and other mispair-binding proteins for mispaired bases. Several observations support this point of view: (1) a mutS allele containing a mutation in the ATP-binding domain (Haber and Walker 1991) causes a complete defect in mismatch repair in vivo. However, the mutant protein can bind, albeit with reduced affinity, to base pair mismatches in vitro. Furthermore, when overexpressed, this mutant is dominant to wild type, suggesting that the mutant protein may be able to bind to base pair mismatches in vivo but is unable to interact with other mismatch repair components. (2) The recent observation of positive cooperativity between ATP binding and mispair binding for Mshl suggests that Mshl undergoes a conformational change when it binds to mispaired bases (Chi and Kolodner 1994b). (3) The identification of a mismatch-containing complex in E. coli involving MutS and MutL, and a similar complex in yeast involving Msh2, Pmsl, and Mlhl, suggests that the formation of an appropriate complex between Msh2 and a mispaired base could result in the recruitment of Mlh1 and Pmsl (Modrich 1991; Prolla et al. 1994b|. A direct prediction of this view is that MutS should not interact with MutL and Msh2 should not interact with Mlhl and Pmsl in the absence of DNA containing a mispaired base. In this regard, Msh2 does not appear to interact with Mlh1 or Pms1 in two-hybrid interaction screens even when both Mlhl and Pmsl are expressed at high levels (Prolla et al. 1994b).

\section{Materials and methods}

\section{Strains}

The E. coli strain RDK 1400 (thr, leuB6, thi, thy A, trpC1117, hsrk12, hsmk12, str r recA13) was from our laboratory collection and was used to amplify and manipulate all plasmids described in this paper. The S. cerevisiae strain BJ5464 ( $\alpha$, ura3-52, trp1, leu2 1 , his $3 \Delta 200$, pep $4:: H I S 3$, prb1 $11.6 R$, can $1, G A L)$ was obtained from the Yeast Genetic Stock Center and was used for the overexpression and purification of Msh2 protein. This strain was transformed with pEN11 and pEN43 plasmids using the lithium acetate method described by Gietz and Schiestl (1992).

\section{Media, reagents, and chemicals}

E. coli strains were grown in LB broth or on LB agar that was supplemented with $100 \mu \mathrm{g} / \mathrm{ml}$ of ampicillin when required (Miller 1972). Yeast strains were grown in either YPD or minimal selective media (Sherman et al. 1983). Selective media contained $0.7 \%$ yeast nitrogen base, $2 \%$ agar, and $0.09 \%$ of a dropout mix that lacks the amino acid used for selection; $2 \%$ glucose, $3 \%$ glycerol, $2 \%$ lactate, and $2 \%$ galactose were included as indicated. When required, canavanine (Sigma) was included in minimal selective media lacking arginine at $60 \mathrm{mg} / \mathrm{liter}$ (Rose et al. 1990).

ATP and GTP were from Pharmacia (Uppsala, Sweden) and BA85, $0.45 \mu \mathrm{M}$ nitrocellulose filters were from Schleicher \& Schuell (Keene, NH). Protein concentrations were determined by the Bradford dye method using bovine serum albumin as a standard (Bradford 1976) and reagents obtained from Bio-Rad (Richmond, CA). Raw ascites fluid containing 12CA5 monoclo- nal antibody was from Berkeley Antibody Company (Richmond, CA). Materials for Western blotting were purchased from Promega (Madison, WI) and used according to the manufacturer's instructions. For column chromatography, PBE 94 was purchased from Pharmacia (Uppsala, Sweden), Bio-Rex 70 was purchased from Bio-Rad, and phosphocellulose P11 was purchased from Whatman (Kent, England); all resins were precycled according to the manufacturer's instructions. Protein standards were myosin $(205 \mathrm{kD})$, $\beta$-galactosidase (116 kD), phosphorylase $\mathrm{B}(97.4 \mathrm{kD})$, serum albumin $(66.2 \mathrm{kD})$, and ovalbumin $(44 \mathrm{kDa})$ and were obtained from Bio-Rad.

Nucleic acid techniques

All restriction endonucleases, T4 polynucleotide kinase, T4 DNA ligase, and T4 DNA polymerase were from New England Biolabs and used according to manufacturer's specifications. Plasmid DNA was isolated by alkaline lysis and all DNA manipulations were performed as described previously (Maniatis et al. 1982). Double-stranded DNA sequencing and the synthesis of oligonucleotides used to make pEN11 was performed at the Molecular Biology Core Facility, Dana Farber Cancer Institute.

\section{Oligonucleotides}

HPLC-purified oligonucleotides were purchased from Operon Technologies, Inc. (Alameda, CA). Oligonucleotides were resuspended and diluted in $1 \times$ TE $[10 \mathrm{~mm}$ Tris $\langle\mathrm{pH} 7.6), 1 \mathrm{mM}$ EDTA and their concentration was determined using an $\epsilon_{260}$ of 12,000 , $15,200,8,400$, and 7,000 for $G, A, T$ and $C$, respectively. Oligonucleotides were 5 ' labeled using $\left[{ }^{32} \mathrm{P} \mid \gamma \mathrm{ATP}\right.$ and $\mathrm{T} 4$ polynucleotide kinase as described previously $/ \mathrm{Chi}$ and Kolodner 1994a|. ${ }^{32}$ P-labeled oligonucleotides were annealed with the complementary strand and then purified on a G25 spin column (Boehringer Mannheim) to remove unincorporated label. Oligonucleotides were annealed by incubating complementary oligonucleotides in $1 \times \mathrm{TE}$ at $95^{\circ} \mathrm{C}$ for $5 \mathrm{~min}$. The oligonucleotides were then transferred to an oil bath incubator at $70^{\circ} \mathrm{C}$ and incubated for an additional $5 \mathrm{~min}$, after which the incubator was turned off and the bath allowed to cool to room temperature $(\sim 2$ $\mathrm{hr}$. After reaching room temperature, the annealed oligonucleotides were diluted in $1 \times \mathrm{TE}$ to the appropriate concentrations before storage.

\section{MSH2 overproducer plasmids}

pEN1 $1(10.3 \mathrm{kB})$ is $2 \mu$ URA3 vector that contains a fusion of the GAL1O promoter to the MSH2-coding region (Fig. 1). This plasmid was constructed from pRDK249 (Johnson and Kolodner 1991), pII-2 (Reenan and Kolodner 1992a), and an oligonucleotide adapter to result in a GAL10-MSH2 fusion that contains the same DNA sequence between the GAL10 promoter and the initiation codon of MSH2, which is present in a GAL1O-SEP1 fusion (Johnson and Kolodner 1991). The junction between GAL1O and MSH2 was confirmed by DNA sequencing.

pEN43 encodes a copy of the MSH2 gene that bears the 12CA5 epitope sequence (Kolodziej and Young 1991). It is identical to pEN11 with the exception of a 33-bp insertion at the NcoI site (bp 1931) in the MSH2 open reading frame, resulting in the insertion of the 12CA5 epitope followed by two additional amino acids (YPYDVPDYAGM) after amino acid 644 in the MSH2 polypeptide sequence (Fig. 1). The sequence of the 33-bp oligonucleotide used to make the insertion is as follows: top strand, 5'-CATGTACCCATACGACGTCCCAGACTACGCTGG, bottom strand, 5'-CATGCCAGCGTAGTCTGGGACGTCGTATGGGTA. This epitope-tagged variant of $M S H 2$ was rec- 
ognized specifically by mAb $12 \mathrm{CA} 5$ (Fig. 2) and could complement fully an msh2 strain as measured by the canavanineresistance assay (Alani et al. 1994).

\section{Overexpression and purification of Msh2}

Yeast strains BJ5464/pEN11 and BJ5464/pEN43 were grown in minimal medium lacking uracil (ura drop out) and induced for MSH2 overexpression using methods described by Johnson and Kolodner (1991). A brief description is as follows. A fresh overnight culture of cells grown in ura drop-out media containing $2 \%$ glucose was diluted into ura drop-out media containing $3 \%$ glycerol and $2 \%$ lactate $(\mathrm{pH} 5.5)$ so that the initial $\mathrm{OD}_{600}$ of the culture was $\sim 0.2$. Cultures were then grown with shaking at $30^{\circ} \mathrm{C}$ until they reached an $\mathrm{OD}_{600}$ of $1.0-1.4(\sim 16 \mathrm{hr})$, after which galactose was added to a final concentration of $2 \%$. Cultures were incubated at $30^{\circ} \mathrm{C}$ for an additional $7 \mathrm{hr}$, after which they were harvested by centrifugation at $4^{\circ} \mathrm{C}$ in a Beckman $\mathrm{J} 6$ 4.2 rotor at $4000 \mathrm{rpm}$ for $10 \mathrm{~min}$, washed once in an ice cold solution containing $100 \mathrm{~mm} \mathrm{NaCl}, 25 \mathrm{~mm}$ Tris (pH 7.6), $1 \mathrm{~mm}$ EDTA, and then stored as cell pellets at $-70^{\circ} \mathrm{C}$. A typical wet weight yield was $2.0 \mathrm{~g}$ of cells/liter.

All chromatography steps were performed at $0-4^{\circ} \mathrm{C}$ and purification was monitored by SDS-PAGE using $10 \%$ polyacrylamide gels (Laemmli 1970), and by measuring binding activity to homoduplex and heteroduplex oligonucleotide substrates. Below are the results from a typical Msh2 purification: $20 \mathrm{~g}$ of frozen cell pellet (BJ5464 containing pEN11 or pEN43) was thawed on ice and resuspended in an equal volume of extraction buffer [buffer A containing $0.25 \mathrm{M} \mathrm{NaCl}$; buffer A contains 25 $\mathrm{mm}$ Tris (pH 7.6), $1 \mathrm{~mm}$ EDTA, $10 \mathrm{~mm} \beta$-mercaptoethanol, $1 \mathrm{~mm}$ PMSF [Sigma)]. Cells were disnupted with three 10 -sec pulses in a $65-\mathrm{ml}$ bead beater chamber containing $0.45-\mu \mathrm{m}$ glass beads as described by Johnson and Kolodner (1991). The cell lysate was recovered and the beads were washed with $\sim 50 \mathrm{ml}$ of extraction buffer. The lysate and wash were pooled $(\sim 90 \mathrm{ml})$ and centrifuged in a Beckman $70 \mathrm{Ti}$ rotor at $36,000 \mathrm{rpm}$ for $30 \mathrm{~min}$. The supernatant (fraction I, $85 \mathrm{ml}, 596 \mathrm{mg}$ ) was directly applied to a $5.0 \mathrm{~cm}^{2} \times 4.4 \mathrm{~cm}$ column of PBE94 at $50 \mathrm{ml} / \mathrm{hr}$, and washed with buffer $\mathrm{A}$ containing $0.25 \mathrm{M} \mathrm{NaCl}$ until the $\mathrm{OD}_{280}$ reached baseline $(\sim 120 \mathrm{ml})$. The column was then eluted with a $250-\mathrm{ml}$ of a linear gradient from 0.25 to $0.65 \mathrm{M} \mathrm{NaCl}$ run in Buffer $\mathrm{A}$ at 50 $\mathrm{ml} / \mathrm{hr}$. Peak fractions containing Msh2 protein eluted at 380 $\mathrm{mM} \mathrm{NaCl}$. These fractions were pooled /fraction II, $28.0 \mathrm{ml}, 10.9$ $\mathrm{mg}$, diluted with buffer A to obtain a conductivity equivalent to buffer $\mathrm{A}$ containing $130 \mathrm{mM} \mathrm{NaCl}$, and then applied to a 0.65 $\mathrm{cm}^{2} \times 1.5 \mathrm{~cm}$ column of Bio-Rex 70 at a flow rate of $5.3 \mathrm{ml} / \mathrm{hr}$. The flow rate was raised to $8.0 \mathrm{ml} / \mathrm{hr}$ for all subsequent steps. After washing with $5 \mathrm{ml}$ of buffer A containing $0.24 \mathrm{M} \mathrm{NaCl}$, the column was eluted with $10 \mathrm{ml}$ of buffer A containing $0.5 \mathrm{M}$ $\mathrm{NaCl}$. Peak fractions of the $0.5 \mathrm{M} \mathrm{NaCl}$ wash were pooled (fraction III, $3.0 \mathrm{ml}, 1.1 \mathrm{mg}$ ), diluted with buffer A to obtain a conductivity equivalent to buffer $\mathrm{A}$ containing $350 \mathrm{mM} \mathrm{NaCl}$, and then applied to a $0.65 \mathrm{~cm}^{2} \times 1.5 \mathrm{~cm}$ column of phosphocellulose $\mathrm{Pll}$ at $8.0 \mathrm{ml} / \mathrm{hr}$. The column was washed with $5.0 \mathrm{ml}$ of buffer A containing $0.4 \mathrm{M} \mathrm{NaCl}$, followed by $5.0 \mathrm{ml}$ of buffer A containing $0.5 \mathrm{M} \mathrm{NaCl}$. Msh2 protein was then eluted with $10 \mathrm{ml}$ of buffer A containing $1.0 \mathrm{M} \mathrm{NaCl}$. Peak fractions were pooled (fraction IV, $0.65 \mathrm{ml}, 0.14 \mathrm{mg}$ ), frozen in aliquots in liquid nitrogen and stored at $-70^{\circ} \mathrm{C}$. The DNA-binding activity of fraction IV was unaffected by storage at $-70^{\circ} \mathrm{C}$ and was unchanged after 6 months of storage.

\section{Immunoprecipitation}

Msh2 protein was immunoprecipitated from either fraction I or fraction III of galactose-induced BJ5464/pEN43 as described be- low. As a control, immunoprecipitations of BJ5464/pEN11, a strain that contains the Msh2 overproducer that lacks the epitope tag, were performed side by side. All incubations were performed at $4^{\circ} \mathrm{C}$ on an oscillating rocker (Vari-mix) and all centrifugation steps were performed using an Eppendorf model 5415 microcentrifuge. $\mathrm{NaCl}$ and Triton $\mathrm{X}-100$ (Sigma) were added to fractions I and III to yield final concentrations of $0.5 \mathrm{M}$ and $1 \%$, respectively. These fractions were then preincubated with protein A-Sepharose CL4B (Pharmacia Uppsala, Sweden) at a ratio of $\sim 1 \mu \mathrm{l}$ of beads/ $\mu \mathrm{g}$ of Msh2 (estimated by SDS-PAGE analysis of the extracts). After a 15-min incubation, the sample was centrifuged at $14,000 \mathrm{rpm}$ for $5 \mathrm{~min}$. The supernatant was then incubated with $\mathrm{mAb} 12 \mathrm{CA} 5$ at a ratio of $\sim 1 \mu \mathrm{l}$ of ascites fluid to $2 \mu \mathrm{g}$ of $\mathrm{Msh} 2$ for $60 \mathrm{~min}$. Protein A-Sepharose was resuspended in an equal volume of $0.5 \mathrm{M} \mathrm{NaCl}, 1 \%$ Triton, and $1 \times$ buffer $A$ and was then added at a ratio of $3.33 \mu l$ of beads $/ \mu l$ of added ascites fluid. After an additional incubation for $50 \mathrm{~min}$, the sample was centrifuged at $2500 \mathrm{rpm}$ for $20 \mathrm{sec}$. The supernatant was removed, and the protein A-Sepharose beads were suspended in 10-bead volume equivalents (the same volume was used in subsequent steps) with $0.5 \mathrm{M} \mathrm{NaCl}, 1 \%$ Triton, $1 \times$ buffer A. The sample was centrifuged and washed with $0.5 \mathrm{M}$ $\mathrm{NaCl}, 1 \%$ Triton, $1 \times$ buffer $\mathrm{A}$ three more times, after which it was washed twice with $50 \mathrm{mM} \mathrm{NaCl}, 20 \mathrm{~mm}$ Tris (pH 7.6), 0.1 mM DTT, $0.01 \mathrm{~mm}$ EDTA. The protein A-Sepharose beads containing bound $\mathrm{Msh} 2$ were then suspended with an equal volume of $50 \mathrm{~mm} \mathrm{NaCl}, 20 \mathrm{mM}$ Tris $(\mathrm{pH} 7.6), 0.1 \mathrm{~mm}$ DTT, $0.01 \mathrm{~mm}$ EDTA, and then used immediately in DNA-binding assays or for analysis by SDS-PAGE.

\section{DNA-binding assays}

The standard buffer for the DNA-binding assay contained 20 mM Tris (pH 7.6), 0.1 mM DTT, $0.01 \mathrm{~mm} \mathrm{EDTA,} \mathrm{and} 40 \mu \mathrm{g} / \mathrm{ml}$ of BSA. Binding was performed at $30^{\circ} \mathrm{C}$ for $15 \mathrm{~min}$ in a $60-120$ $\mu \mathrm{l}$ reaction, and each reaction contained $11.7 \mathrm{nM}$ of ${ }^{32} \mathrm{P}$-labeled duplex oligonucleotide, 0-1333 nM of unlabeled competitor duplex oligonucleotide, and $0-0.84 \mu \mathrm{g}$ of Msh2 fraction IV. After incubation, samples were analyzed by filter binding to $\mathrm{KOH}$ treated nitrocellulose filters (McEntee et al. 1980) using a Hoeffer Scientific Instruments FH225V filtering unit (San Francisco, CA). A detailed description of the filter-binding protocol has been described by Chi and Kolodner (1994a). The relative effectiveness of different competitor DNAs in detailed titration experiments was determined from log versus log plots of the data as described previously (Chi and Kolodner 1994a).

Binding complexes were also detected by gel retardation using methods described previously (Hennighausen and Lubon 1987). These assays differed from filter-binding assays in that they were performed in $10 \mu \mathrm{l}$ reactions and also contained $12 \%$ glycerol ( $\mathrm{vol} / \mathrm{vol}$ ) and $50 \mathrm{ng}$ of poly [d(I-C)] (Boehringer Mannheim). Furthermore, binding was performed for $30 \mathrm{~min}$ on ice. After incubation, $5 \mu \mathrm{l}$ aliquots were loaded onto a $5 \%$ nondenaturing acrylamide gel containing $0.25 \times$ TBE $(\mathrm{pH} 8.0)$. Samples were electrophoresed at $4^{\circ} \mathrm{C}$ in $0.25 \times \mathrm{TBE}$ at $10 \mathrm{~V} / \mathrm{cm}$ until the bromophenol blue dye marker that had been added to a blank sample had migrated $75 \%$ of the distance to the end of the gel. The gels were then dried and scanned using a Molecular Dynamics PhosphorImager.

DNA-binding assays were also performed using immunoprecipitated Msh2 that remained conjugated to protein A-Sepharose. Binding was performed in $16-\mu 1$ reactions in standard buffer containing $50 \mathrm{~mm} \mathrm{NaCl}$ but lacking BSA. These reactions contained $5 \mu \mathrm{l}$ of protein A-Sepharose beads bearing various amounts of bound Msh2 protein, and ${ }^{32} \mathrm{P}$-labeled duplex oligonucleotide and unlabeled competitor at concentrations similar 
to those used in the filter-binding assay. The reaction tubes were incubated at room temperature on a Vari-mix rocker to maintain the protein A-Sepharose beads in suspension. After a 60-min incubation, the samples were centrifuged at $2500 \mathrm{rpm}$ for $20 \mathrm{sec}$ to remove the supernatant. The samples were then suspended with $75 \mu$ l of standard buffer containing $50 \mathrm{mM} \mathrm{NaCl}$ but lacking BSA, centrifuged as before to remove the supernatant and then suspended in $400 \mu l$ of the same buffer. The samples were then centrifuged to remove the supernatant, and the amount of DNA bound to the beads was determined by scintil. lation counting.

\section{Acknowledgments}

We are extremely grateful to Arlen Johnson, Gerry Marsischky, Keiko Umezu, and Rolf Freter for technical advice and helpful discussions. This work was supported by National Institutes of Health grant HG00305/GM50006 to R.D.K. and Cancer Center Core Grant CA06516 to the Dana Farber Cancer Institute. E.A. is a Merck Fellow of the Life Sciences Research Foundation.

The publication costs of this article were defrayed in part by payment of page charges. This article must therefore be hereby marked "advertisement" in accordance with 18 USC section 1734 solely to indicate this fact.

\section{References}

Alani, E., R.A.G. Reenan, and R.D. Kolodner. 1994. Interaction between mismatch repair and genetic recombination in Saccharomyces cerevisiae. Genetics 137: 19-39.

Bishop, D.K. and R. Kolodner. 1986. Repair of heteroduplex plasmid DNA after transformation into Saccharomyces cerevisiae. Mol. Cell. Biol. 6: 3401-3409.

Bishop, D.K., M.S. Williamson, S. Fogel, and R. Kolodner. 1987. The role of heteroduplex correction in gene conversion in Saccharomyces cerevisiae. Nature 328: 362-364.

Bishop, D.K., J. Andersen, and R.D. Kolodner. 1989. Specificity of mismatch repair following transformation of Saccharomyces cerevisiae with heteroduplex plasmid DNA. Proc. Natl. Acad. Sci. 86: 3713-3717.

Bradford, M.M. 1976. A rapid and sensitive method for the quantitation of microgram quantities of protein utilizing the principle of protein-dye binding. Anal. Biochem. 72: 248254.

Bronner, C.E., S.M. Baker, P.T. Morrison, G. Warren, L.G. Smith, M. Lescoe, M. Kane, C. Earabino, J. Lipford, A. Lindblom, P. Tannergard, R.J. Bollag, A.R. Godwin, D.C. Ward, M. Nordenskjold, R. Fishel, R. Kolodner, and R.M. Liskay. 1994. Mutation in the DNA mismatch repair gene homologue $h M L H 1$ is associated with hereditary non-polyposis colon cancer. Nature 368: 258-261.

Burns, N., B. Grimwade, P.B. Ross-Macdonald, E. Choi, K. Finberg, G.S. Roeder, and M. Snyder. 1994. Large-scale analysis of gene expression, protein localization and gene disruption in Saccharomyces cerevisiae. Genes \& Dev. 8: 1087-1105.

Cantor, C.R. and P. Schimmel. 1980. Biophysical chemistry. Part III: The behavior of biological macromolecules. W.H. Freeman, San Francisco, CA.

Chi, N. and R.D. Kolodner. 1994a. Purification and characterization of Msh1, a yeast mitochondrial protein that binds to DNA mismatches. J. Biol. Chem. 269: 29984-29992.

- 1994b. The effect of DNA mismatches on the ATPase activity of Mshl, a protein in yeast mitochondria that recognizes DNA mismatches. J. Biol. Chem. 269: 29993-29997.

Donahue, T.F., P.J. Farabaugh, and G.R. Fink. 1982. The nucle- otide sequence of the HIS4 region of yeast. Gene 18: 47-59.

Fishel, R., M.K. Lescoe, M.R.S. Rao, N.G. Copeland, N.A. Jenkins, J. Garber, M. Kane, and R.D. Kolodner. 1993. The human mutator gene homolog Msh2 and its association with hereditary nonpolyposis colon cancer. Cell 75: 1027-1038.

Fishel, R., A. Ewel, S. Lee, M.K. Lescoe, and J. Griffith. 1994. Binding of mismatched microsatellite DNA sequences by the human MSH2 protein. Science 266: 1403-1405.

Geitz, R.D. and R.H. Schiestl. 1991. Applications of high efficiency lithium acetate transformation of intact yeast cells using single-stranded nucleic acids as carrier. Yeast 7:253263.

Haber, L.T. and G.C. Walker. 1991. Altering the conserved nucleotide binding motif in the Salmonella typhimurium MutS mismatch repair protein affects both its ATPase and mismatch binding activities. EMBO I. 10: 2707-2715.

Hennighausen, L. and H. Lubon. 1987. Interaction of protein with DNA in vitro: Guide to molecular cloning techniques. Methods Enzymol. 152: 721-735.

Holmes, J.J., S. Clark, and P. Modrich. 1990. Strand specific mismatch correction in nuclear extracts of human and Drosphila melanogaster cell lines. Proc. Natl. Acad. Sci. 87: 5837-5841.

Hughes, M.J. and J. Jiricny. 1992. The purification of a human mismatch-binding protein and identification of its associated ATPase and helicase activities. I. Biol. Chem. 267: 23876-23882.

Jiricny, J., S. Su, S.G. Wood, and P. Modrich. 1988. Mismatchcontaining oligonucleotide duplexes bound by the $E$. coli mutS-encoded protein. Nucleic Acids. Res. 16: 7843-7853.

Johnson, A.W. and R.D. Kolodner. 1991. Strand exchange protein I from Saccharomyces cerevisiae: A novel multifunctional protein that contains DNA strand exchange and exonuclease activities. I. Biol. Chem. 266: 4046-14054.

Jones, M. and M. Radman. 1987. Repair of a mismatch is influenced by the base composition of the surrounding nucleotide sequence. Genetics 115: 605-610.

Kolodner, R.D., N.R. Hall, I.R. Lipford, M.F. Kane, M.R.S. Rao, P. Morrison, L. Wirth, P.J. Finan, J. Burn, P. Chapman, C. Earabino, E. Merchant, and D.T. Bishop. 1994. Structure of the human MSH2 locus and analysis of two Muir-Torre kindreds for msh2 mutations. Genomics 24: 516-526.

Kolodziej, P.A. and R.A. Young. 1991. Epitope tagging and protein surveillance. Methods Enzymol. 194: 508-519.

Kramer, B., W. Kramer, M.S. Williamson, and S. Fogel. 1989a. Heteroduplex DNA correction in Saccharomyces cerevisiae is mismatch repair specific and requires functional $P M S$ genes. Mol. Cell. Biol. 9: 4432-4440.

1989b. Cloning and nucleotide sequence of DNA mismatch repair gene PMS1 from Saccharomyces cerevisiae: Homology of PMS1 to procaryotic mutL and hexB. I. Bacteriol. 171: 5339-5346.

Laemmli, U.K. 1970. Cleavage of structural proteins during the assembly of the head of bacteriophage T4. Nature 227: 680685.

Lahue, R.S., K.G. Au., and P. Modrich. 1989. DNA mismatch correction in a defined system. Science 245: 160-164.

Leach, F.S., N.C. Nicolaides, N. Papadopoulos, B. Liu, J. Jen, R. Parsons, P. Peltomaki, P. Sistonen, L.A. Aaltonen, M. Nystrom-Lahti, X.-Y. Guan, J. Zhang, P.S. Meltzer., J.-W. Yu, F.-T. Kao, D.J. Chen, K.M. Cerosaletti, R.E.K. Fournier, S. Todd, T. Lewis, R.J. Leach, S.L. Naylor, J. Weissenbach, J.-P. Mecklin, H. Jarvinen, G.M. Petersen, S.R. Hamilton, J. Green, J. Jass, P. Watson, H.T. Lynch, J.M. Trent. A. de la Chapelle, K.W. Kinzler, and B. Vogelstein. 1993. Mutations of a MutS homolog in hereditary nonpolyposis colorectal 
cancer. Cell 75: 1215-1225.

Levinson, G. and G.A. Gutman. 1987. High frequencies of short frameshifts in poly-CA/TG tandem repeats borne by bacteriophage M13 in Escherichia coli K-12. Nucleic Acids Res. 15: $5313-5338$.

Maniatis, T., E.F. Fritsch, and J. Sambrook. 1982. Molecular cloning: A laboratory manual. Cold Spring Harbor Laboratory, Cold Spring Harbor, New York.

McEntee, K., G. Weinstock, and I.R. Lehman. 1980. recA protein-catalyzed strand assimilation: Stimulation by Escherichia coli single-stranded DNA-binding protein. Proc. Natl. Acad. Sci. 77: 857-861.

Miller, J. 1972. Experiments in molecular genetics. Cold Spring Harbor Laboratory, Cold Spring Harbor, New York.

Miret, J.J., M.G. Milla, and R.S. Lahue. 1993. Characterization of a DNA mismatch-binding activity in yeast extracts. I. Biol. Chem. 268: 3507-3513.

Modrich, P. 1991. Mechanisms and biological effects of mismatch repair. Annu. Rev. Genet. 25: 229-253.

Muster-Nassal, C. and R.D. Kolodner. 1986. Mismatch correction catalyzed by cell-free extracts of Saccharomyces cerevisiae. Proc. Natl. Acad. Sci. 83: 7618-7622.

Nag, D.K. and T.D. Petes. 1991. Seven-base-pair inverted repeats in DNA form stable hairpin in vivo in Saccharomyces cerevisiae. Genetics 129: 669-673.

New, L., K. Liu, and G.F. Crouse. 1993. The yeast gene MSH3 defines a new class of eukaryotic MutS homologues. Mol. \& Gen. Genet. 239: 97-108.

Nicolaides, N.C., N. Papadopoulos, B. Liu, Y. Wei, K.C. Carter, S. M. Ruben, C.A. Rosen, W.A. Haseltine, R.D. Fleischmann, C.M. Fraser, M.D. Adams, J.C. Venter, M.G. Dunlop, S.R. Hamilton, G.M. Petersen, A. de la Chapelle, B. Vogelstein, and K. Kinzler. 1994. Mutations of two PMS homologues in hereditary nonpolyposis colon cancer. Nature 371: $75-80$.

Palombo, F., M. Hughes, J. Jiricny, O. Truong, and J. Hsuan. 1994. Mismatch repair and cancer. Nature 367:417.

Papadopoulos, N., N.C. Nicolaides, Y.-F. Wei, S.M. Ruben, K.C. Carter, C.A. Rosen, W.A. Haseltine, R.D. Fleischmann, C.M. Fraser, M.D. Adams, J.C. Venter, S.R. Hamilton, G.M. Petersen, P. Watson, H.T. Lynch, P. Peltomaki, J.-P. Mecklin, A. de la Chapelle, K.W. Kinzler, and B. Vogelstein. 1994. Mutation of a mutL homolog in hereditary colon cancer. Science 263: 1625-1628.

Parker, B.O. and M.G. Marinus. 1992. Repair of DNA heteroduplexes containing small heterologous sequences in Esche richia coli. Proc. Natl. Acad. Sci. 89: 1730-1734.

Parsons, R., G. Li, M.J. Longley, W. Fang, N. Papadopoulos, J. Jen, A. de la Chapelle, K. W. Kinzler, B. Vogelstein, and P. Modrich. 1993. Hypermutability and mismatch repair deficiency in RER + tumor cells. Cell 75: 1227-1236.

Petes, T.D., R.E. Malone, and L.S. Symington. 1991. Recombination in yeast. In The molecular and cellular biology of the yeast Saccharomyces: Genome dynamics, protein synthesis and energetics (ed. J.R. Broach, J.R. Pringle, and E.W. Jones), pp. 407-521. Cold Spring Harbor Laboratory, Cold Spring Harbor, New York.

Prolla, T.A., D.M. Christie, and R.M. Liskay. 1994a. Dual requirment in yeast DNA mismatch repair for $M L H 1$ and PMS1, two homologs of the bacterial mutL gene. Mol. Cell. Biol. 14: 407-415.

Prolla, T.A., Q. Pang, E. Alani, R.D. Kolodner, and R.M. Liskay. 1994b. Interactions between the Msh2, Mlh1 and Pms1 proteins during the initiation of DNA mismatch repair. Science 265: 1091-1093.

Reenan, R.A.G. and R.D. Kolodner. 1992a. Isolation and char- acterization of two Saccharomyces cerevisiae genes encoding homologs of the bacterial HexA and MutS mismatch repair proteins. Genetics 132: 963-973.

. 1992b. Characterization of insertion mutations in the Saccharomyces cerevisiae MSH1 and MSH2 genes: Evidence for separate mitochondrial and nuclear functions. Genetics 132: 975-985.

Rose, M.D., F. Winston, and P. Hieter. 1990. Methods in yeast genetics. A laboratory course manual. Cold Spring Harbor Laboratory Press, Cold Spring Harbor, New York.

Sherman, F., G. Fink, and J. Hicks. 1983. Methods in yeast genetics. Cold Spring Harbor Laboratory, Cold Spring Harbor, New York.

Strand, M., T.A. Prolla, R.M. Liskay, and T.D. Petes. 1993. Destabilization of tracts of simple repetitive DNA in yeast by mutations affecting DNA mismatch repair. Nature 365: 274-276

$\mathrm{Su}, \mathrm{S}$. and P. Modrich. 1986. Escherichia coli mutS-encoded protein binds to mismatched DNA base pairs. Proc. Natl. Acad. Sci. 83: 5057-5061.

$\mathrm{Su}$, S., R.S. Lahue, K.G. Au, and P. Modrich. 1988. Mispair specificity of methyl-directed DNA mismatch correction in vitro. I. Biol. Chem. 263: 6829-6835.

Thomas, D.C., J.D. Roberts, and T.A. Kunkel. 1991. Heteroduplex repair in extracts of human HeLa cells. I. Biol. Chem. 266: 3744-3751.

Umar, A., J.C. Boyer, and T.A. Kunkel. 1994a. DNA loop repair by human cell extracts. Science 266: 814-816.

Umar, A., J.C. Boyer, D.C. Thomas, D.C. Nguyen, J.I. Risinger, J. Boyd, Y. Ionov, M. Perucho, and T.A. Kunkel. 1994b. Defective mismatch repair in extracts of colorectal and endometrial cancer cell lines exhibiting microsatellite instability. I. Biol. Chem 269: 14367-14370.

Varlet, I., M. Radman, and P. Brooks. 1990. DNA mismatch repair in Xenopus egg extracts: Repair efficiency and DNA repair synthesis for all single base-pair mismatches. Proc. Natl. Acad. Sci. 87: 7883-7887. 


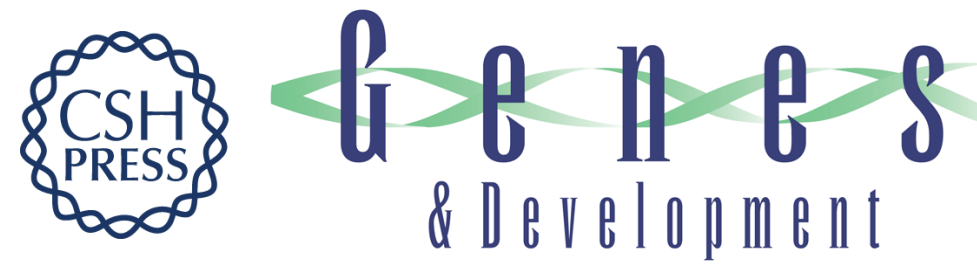

\section{The Saccharomyces cerevisiae Msh2 protein specifically binds to duplex oligonucleotides containing mismatched DNA base pairs and insertions.}

E Alani, N W Chi and R Kolodner

Genes Dev. 1995, 9:

Access the most recent version at doi:10.1101/gad.9.2.234

References This article cites 50 articles, 29 of which can be accessed free at: http://genesdev.cshlp.org/content/9/2/234.full.html\#ref-list-1

License

Email Alerting Service

Receive free email alerts when new articles cite this article - sign up in the box at the top right corner of the article or click here.

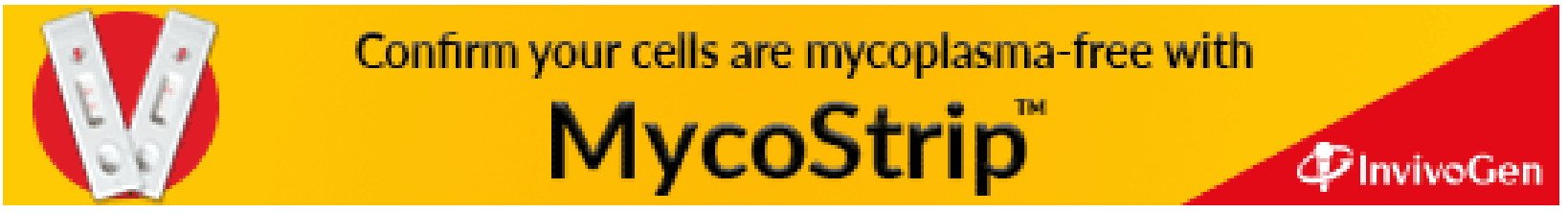

